\title{
Fungos, criptógamas e outros palinomorfos holocênicos (7908 \pm 30 anos AP-atual) da Planície Costeira sul-catarinense, Brasil ${ }^{1}$
}

Rodrigo Rodrigues Cancelli ${ }^{2,4}$, Paulo Alves de Souza ${ }^{2}$ e Paulo César Pereira das Neves ${ }^{3}$

Recebido em 20/06/2011. Aceito em 31/10/2011

\begin{abstract}
RESUMO
(Fungos, criptógamas e outros palinomorfos holocênicos (7908 \pm 30 anos AP-atual) da Planície Costeira sul-catarinense, Brasil). Neste estudo são apresentados os resultados palinológicos qualitativos equivalentes às análises paleoambientais realizadas em duas seções turfáceas na Planície Costeira sul do estado de Santa Catarina, nos municípios de Santa Rosa do Sul e São João do Sul. Uma amostra da base do testemunho de Santa Rosa do Sul foi datada $\left({ }^{14} \mathrm{C}\right)$ em $7908 \pm 33$ anos AP, referente ao Holoceno inferior. A análise palinológica permitiu identificações taxonômicas, com descrições e ilustrações de 54 palinomorfos, relativos a fungos (21), algas (5), acritarcas (1), incertae sedis (1), briófitos (2), pteridófitos (15), pólen de gimnospermas (2), e outros palinomorfos (1 cápsula de briófitos, 4 fragmentos de invertebrados e 2 palinoforaminíferos indeterminados), cujos registros modernos expressam diferentes hábitos de vida. O trabalho tem como objetivos contribuir para o conhecimento dos vestígios da vegetação e táxons relacionados depositados na Planície Costeira sul-catarinense durante o Holoceno. As análises palinológicas conseguintes auxiliarão na interpretação dos paleoambientes e paleoclimas relacionados neste setor da costa brasileira.
\end{abstract}

Palavras-chave: Holoceno; Palinologia, Planície Costeira; Quaternário, Santa Catarina

\begin{abstract}
(Fungi, cryptogams and other palynomorphs in the Holocene sediments of the South Coastal Plain of Santa Catarina, Brazil). This paper presents the results of a palynological analysis carried out on two cores taken from the south Coastal Plain of the Santa Rosa do Sul and São João do Sul municipalities, in the state of Santa Catarina. A basal sample from the Santa Rosa do Sul core furnished a ${ }^{14} \mathrm{C}$ age of $7908 \pm 33$ yr BP, from the Lower Holocene. Palynological analysis of the material allowed for taxonomic identifications, and resulted in descriptions and illustrations of 54 palynomorphs related to fungi (21), algae (5), acritarchs (1), incertae sedis (1), bryophytes (2), ferns (15), gymnosperm pollen (2) and other palynomorphs ( 1 bryophyte capsule, 4 invertebrate fragments, and 2 indeterminate palynoforaminifers), which express different ecological patterns. This work aimed to contribute to the knowledge of the plant and fungal fossils remains, and related taxa, recorded from the Coastal Plain of Santa Catarina for the Holocene. Additional palynological analyses will contribute to paleoclimate and paleoenvironmental interpretations of this portion of the Brazilian coast.
\end{abstract}

Key words: Holocene, Palynology, Coastal Plain, Quaternary, Santa Catarina

\section{Introdução}

A identificação dos palinomorfos preservados em sedimentos quaternários é uma ferramenta importante que permite o melhor conhecimento das floras pretéritas. As interpretações posteriores, através dos parâmetros da ecologia moderna representados pelos mesmos, contribuem para o entendimento das dinâmicas e dos processos envolvidos na gênese das formações vegetacionais ao longo do tempo, bem como dos paleoambientes deposicionais. Estes reconhecimentos constituem recurso fundamental nas análises paleoclimáticas do Quaternário.

Para o sul do Brasil, nas últimas décadas, estes regimes climáticos têm sido discutidos em diversos trabalhos de palinologia do Quaternário, tais como: Behling (1993, 1995, 1998, 2002); Neves (1991, 1998); Neves \& Lorscheitter (1992, 1995a, 1995b, 1996); Behling et al. (2001, 2004,

\footnotetext{
Parte da tese de Doutorado do primeiro Autor

2 Universidade Federal do Rio Grande do Sul, Programa de Pós-Graduação em Geociências, Departamento de Paleontologia e Estratigrafia, Laboratório de Palinologia Marleni Marques Toigo, Porto Alegre, RS, Brasil

3 Universidade Luterana do Brasil, Laboratório de Geologia e Mineralogia, Canoas, RS, Brasil

4 Autor para correspondência: rodrigocancelli@hotmail.com
} 
2007); De Oliveira et al. (2005); Leal \& Lorscheitter (2007) e Macedo et al. (2010), dentre outros.

Os dados palinológicos, mostram para a planície costeira do sul do país alternância e/ou sucessão de palinomorfos relacionados aos ambientes marinho, transicional e continental (e.g. Burjack \& Marques-Toigo 1980; Lorscheitter 1983, 1984, 2003; Lorscheitter \& Romero 1985; Neves \& Lorscheitter 1992, 1995b, 1996; Neves 1991, 1998; Behling \& Negrelle 2001; Bauermann et al. 2005; Macedo et al. 2007). Oscilações significativas da frequência relativa dos elementos marinhos atribuídos à última transgressão holocênica e, posteriormente, o desenvolvimento de ecossistemas importantes como as matas de restinga e paludosa, caracterizam os conjuntos palinológicos recuperados nessas áreas.

O estado de Santa Catarina está inserido no bioma Mata Atlântica, que apresenta uma das maiores biodiversidades do planeta, apesar de estar hoje reduzido e bastante fragmentado. A excepcional pujança deste bioma pode ser explicada por uma série de processos naturais que compreendem regimes climáticos provenientes de diversas latitudes (Backes \& Irgang 2004; Mamede et al. 2004).

Para Santa Catarina a contribuição de Behling \& Negrelle (2001) na localidade de Volta Velha, constitui até o momento o único trabalho publicado em palinologia do Quaternário para região costeira.

Nesta região predominam grandes planícies quaternárias de sedimentação marinha, lagunar e terrestre, onde atualmente ocorre uma floresta muito característica e adaptada às condições edáficas especiais de planícies úmidas (Klein 1978).

Este trabalho consiste na primeira documentação dos palinomorfos holocênicos, para o setor sul da Planície Costeira catarinense, como parte de um estudo maior em desenvolvimento na região. Dessa forma são apresentadas descrições dos palinomorfos recuperados ao longo de dois perfis estratigráficos coletados em Santa Rosa do Sul e São João do Sul, objetivando contribuir para o conhecimento dos constituintes de parede orgânica com análogos modernos.

\section{Área de estudo}

A Planície Costeira do estado de Santa Catarina encontra-se na costa sul do Brasil, apresenta cerca de $538 \mathrm{~km}$ de extensão, correspondendo a cerca de 7\% do litoral brasileiro.

Os depósitos paludais identificados nesta região situam-se na porção emersa da Bacia de Pelotas, a mais meridional da margem continental brasileira. A seção quaternária desta bacia engloba depósitos de leques aluviais e de quatro sistemas laguna-barreira, depositados nos últimos 400.000 anos AP em decorrência de eventos transgressivos de cunho glacio-eustático (Villwock \& Tomazelli 1995).

A área de estudo compreende fitogeograficamente a Floresta Tropical das Planícies Quaternárias do Sul (Klein 1978), que se estende entre Jaguaruna-Tubarão e o extremo sul (Sombrio e Praia Grande). A vegetação atual é classifi- cada como Floresta Ombrófila Densa ou Floresta Tropical Fluvial (IBGE 1992).

Segundo Nimer (1979), o clima da região sul catarinense caracteriza-se como mesotérmico úmido, com umidade relativa média do ar em torno de $82,1 \%$. A temperatura média anual é de $19,1^{\circ} \mathrm{C}$, permanecendo a temperatura média das máximas de $24,6^{\circ} \mathrm{C}$ e das mínimas de $14^{\circ} \mathrm{C}$. As maiores temperaturas ocorrem próximo ao litoral, diminuindo gradativamente em direção a oeste.

$\mathrm{O}$ litoral catarinense tem influência do Anticiclone do Atlântico e do Anticiclone Migratório Polar Atlântico (Diehl \& Horn 1996). O primeiro constitui-se na fonte geradora da Massa Tropical Atlântica e o segundo da Massa Polar Atlântica. A Frente Polar Atlântica, resultado do contato entre as duas massas é a responsável por parte da precipitação do litoral, controlada pela presença da Serra do Mar, das serras do Leste Catarinense e da Serra Geral. As precipitações totais anuais são maiores no litoral norte alcançando $1.800 \mathrm{~mm}$ e menores a sul $1.400 \mathrm{~mm}$ (área de estudo).

\section{Material e métodos}

Os perfis sedimentares estudados foram coletados nos municípios de Santa Rosa do Sul ( $29^{\circ} 10^{\circ} 42^{\prime}$ 'S $\left.-49^{\circ} 44^{\prime} 58^{\prime \prime} \mathrm{W}\right)$ e São João do Sul $\left(29^{\circ} 10^{\prime} 42^{\prime \prime}\right.$ 'S $\left.49^{\circ} 44^{\prime} 58^{\prime \prime} \mathrm{W}\right)$, sendo o acesso local das perfurações, feitos pela rodovia BR $101 \mathrm{e}$, posteriormente, através de estradas vicinais (Fig. 1).

A coleta do material foi realizada no interior de matas paludiais próximas à Lagoa do Sombrio, a mais extensa do estado de Santa Catarina, situando-se entre cinco municípios do extremo sul catarinense (Sombrio, Santa Rosa do Sul, Balneário Gaivota, São João do Sul e Passo de Torres), com aproximadamente $16,368 \mathrm{~km}$ de comprimento e cerca de $5 \mathrm{~km}$ de largura. A área da lagoa tem cerca de $54 \mathrm{~km}^{2}$, com profundidade máxima de $4 \mathrm{~m}$.

Os testemunhos foram coletados com aparelho Russian Peat Borer (Moore et al. 1991) atingindo a profundidade de $570 \mathrm{~cm}$ para Santa Rosa do Sul e $260 \mathrm{~cm}$ o de São João do Sul. Em laboratório foram retiradas 57 unidades amostrais do testemunho de Santa Rosa do Sul e, 26 de São João do Sul, respectivamente, com intervalos de $10 \mathrm{~cm}$ e com volumes de $1 \mathrm{~cm}^{3}$ cada. A datação radiocarbônica do nível basal de Santa Rosa do Sul foi obtida através do método Accelerator Mass Spectometry (AMS), realizada no Center for Applied Isotope Studies (CAIS), University of Georgia, USA, e acusou idade de calibração de $7.908 \pm 33$ anos AP. A recuperação dos palinomorfos a partir do processamento químico dos sedimentos foi realizada conforme as técnicas usuais em palinologia do Quaternário, seguindo as orientações de Erdtman (1952), com adaptações de Faegri \& Iversen (1989). Para montagem das lâminas foi utilizada a metodologia de Quadros \& Melo (1987).

As análises qualitativas foram realizadas sob microscopia óptica em aumentos de 400 e 1.000x, utilizando-se microscópios Olympus CX-31 do Laboratório de Palino- 

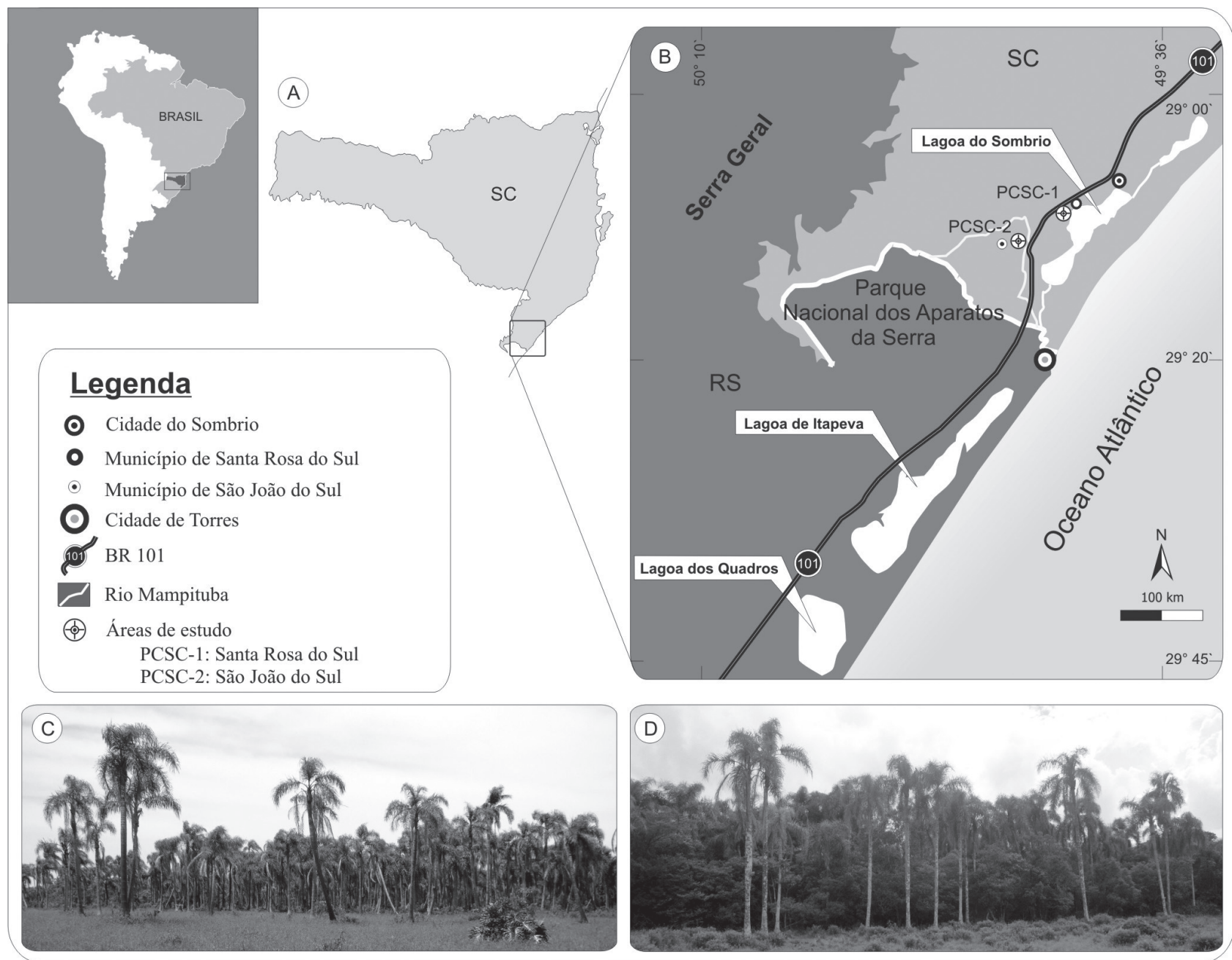

Figura 1. Localização da área de estudo (A-B), com destaque às perfurações de Santa Rosa do Sul (PCSC-1) e São João do Sul (PCSC-2); imagens locais da área de coleta das duas perfurações, respectivamente (C-D).

logia Marleni Marques Toigo do Instituto de Geociências da Universidade Federal do Rio Grande do Sul. A identificação dos palinomorfos foi realizada por comparação com outros materiais de consulta e consequentemente com seus equivalentes modernos, através de consulta à coleção de referência, atlas, catálogos e bibliografia especializada, tais como: Heusser (1971), Markgraf \& D’ Antoni (1978), van Geel (1978), van Geel \& van der Hammen (1977), Hooghiemstra (1984), Lorscheitter $(1988,1989)$, Roubik \& Moreno (1991), Behling (1993), Neves \& Lorscheitter (1992, 1995a), Lorscheitter et al. (1998, 1999, 2001, 2002, 2005), Colinvaux et al. (1999), Kalgutkar \& Jansonius 2000, Neves \& Bauermann $(2003,2004)$, Leal \& Lorscheitter (2006), Medeanic (2006), Neves \& Cancelli (2006), Leonhardt \& Lorscheitter (2007), Roth \& Lorscheitter (2008), Scherer \& Lorscheitter (2008) e Macedo et al. (2009).

Na identificação sistemática procurou-se alcançar a categoria taxonômica de menor nível hierárquico. Em alguns casos, foi utilizada uma identificação categórica (ex: esporo indeterminado 1 ou palinoforaminífero 1). Para as espécies que apresentaram morfologia relacionada a mais de um grupo taxonômico ou sistematicamente aparentada não sendo possível distingui-los, optou-se por utilizar a denominação "tipo" precedida de nomes consagrados na literatura. A terminologia descritiva seguem Barth \& Melhem (1988) e Punt et al. (2007). As descrições morfológicas foram realizadas de forma sucinta caracterizando o mais objetivamente o material identificado, com medidas de tamanho, ornamentação e as aberturas.

Os palinomorfos são apresentados em ordenação evolutiva, utilizando-se Alexopoulos et al. (1996) e Index Fungorum (2009), para fungos; Bold et al. (1987) e Guiry \& Dhonncha (2004), para algas, briófitos e gimnospermas; Tryon \& Tryon (1982), para pteridófitos; van Geel (1978) e Ruppert \& Barnes (1996), para os táxons de animais. As fotomicrografias foram realizadas em microscopia sob aumento de $1.000 \mathrm{x}$, com máquina digital acoplada (Olympus modelo Evolt $€$ 330). As informações sobre as respectivas numerações das lâminas e coordenadas "England Finder" são informadas no Quadro 1. As 
Quadro 1. Lista dos táxons ilustrados, com identificação das lâminas e coordenadas England Finder.

\begin{tabular}{|c|c|c|c|c|}
\hline \multirow[t]{2}{*}{ Palinomorfos } & \multicolumn{2}{|c|}{ Ocorrências } & \multirow{2}{*}{$\begin{array}{c}\text { Coordenadas } \\
\text { MP-P/England Finder }\end{array}$} & \multirow[t]{2}{*}{ Figuras } \\
\hline & PCSC-1 & PCSC-2 & & \\
\hline 1. Glomus & $\mathrm{X}$ & $\mathrm{X}$ & $6523 / \mathrm{K}-26.3$ & Fig. 1 \\
\hline 2. Gelanispora calospora & $\mathrm{X}$ & $\mathrm{X}$ & $6422 / \mathrm{O}-51.1$ & Fig. 2 \\
\hline 3. Gelanispora reticulispora & $\mathrm{X}$ & $\mathrm{X}$ & 6524/G-65.4 & Fig. 3 \\
\hline 4. Neurospora & $\mathrm{X}$ & $\mathrm{X}$ & $6476 / Y-67.4$ & Fig. 4 \\
\hline 5. Helicoon pluriseptatum & $\mathrm{X}$ & $\mathrm{X}$ & $6445 / J-46.3$ & Fig. 5 \\
\hline 6. Microthyrium & $\mathrm{X}$ & $\mathrm{X}$ & $6435 / B-27.4$ & Fig. 6 \\
\hline 7. Bryophytomyces sphagni & $\mathrm{X}$ & $\mathrm{X}$ & $6422 / \mathrm{O}-42.3$ & Fig. 7 \\
\hline 8. tipo Gaeumannomyces & $\mathrm{X}$ & $\mathrm{X}$ & $6492 / \mathrm{U}-53.4$ & Fig. 8 \\
\hline 9. tipo Athelia & $\mathrm{X}$ & $\mathrm{X}$ & $6466 / \mathrm{W}-58.0$ & Fig. 9 \\
\hline 10. tipo Nigrospora & $\mathrm{X}$ & $\mathrm{X}$ & $6440 / \mathrm{M}-48.3$ & Fig. 10 \\
\hline 11. Esporo indeterminado 1 & $\mathrm{X}$ & $\mathrm{X}$ & 6524/P-63.4 & Fig. 11 \\
\hline 12. Esporo indeterminado 2 & $\mathrm{X}$ & $\mathrm{X}$ & $5425 / \mathrm{B}-37.2$ & Fig. 12 \\
\hline 13. Esporo indeterminado 3 & $\mathrm{X}$ & $\mathrm{X}$ & $6473 / \mathrm{W}-60.2$ & Fig. 13 \\
\hline 14. Esporo indeterminado 4 & $\mathrm{X}$ & $\mathrm{X}$ & $5488 / \mathrm{F}-41.3$ & Fig. 14 \\
\hline 15. Esporo indeterminado 5 & $\mathrm{X}$ & $\mathrm{X}$ & $5421 / \mathrm{D}-41.1$ & Fig. 15 \\
\hline 16. Esporo indeterminado 6 & $\mathrm{X}$ & & $5425 / \mathrm{S}-33.3$ & Fig. 16 \\
\hline 17. Esporo indeterminado 7 & $\mathrm{X}$ & & $5421 / \mathrm{S}-27.3$ & Fig. 17 \\
\hline 18. Esporo indeterminado 8 & $\mathrm{X}$ & & $5421 / \mathrm{V}-49.4$ & Fig. 18 \\
\hline 19. Esporo indeterminado 9 & $\mathrm{X}$ & & $6423 / \mathrm{V}-41.2$ & Fig. 19 \\
\hline 20. Esporo indeterminado 10 & $\mathrm{X}$ & & $6523 / \mathrm{K}-26.4$ & Fig. 20 \\
\hline 21. Hifas & $\mathrm{X}$ & $\mathrm{X}$ & 6430/P-53.4 & Fig. 21 \\
\hline 22. Botryococcus & $\mathrm{X}$ & $\mathrm{X}$ & $6478 / \mathrm{S}-38.4$ & Fig. 22 \\
\hline 23. Debarya & $\mathrm{X}$ & $\mathrm{X}$ & $6528 / \mathrm{V}-45.3$ & Fig. 23 \\
\hline 24. tipo Mougeotia laetevires & $\mathrm{X}$ & $\mathrm{x}$ & $6531 / \mathrm{G}-53.3$ & Fig. 24 \\
\hline 25. Spirogyra & $\mathrm{X}$ & $\mathrm{X}$ & $6455 / \mathrm{H}-46.1$ & Fig. 25 \\
\hline 26. Zygnema & $\mathrm{X}$ & $\mathrm{X}$ & $5422 / \mathrm{T}-48.3$ & Fig. 26 \\
\hline 27. tipo Micrhystridium & $\mathrm{X}$ & $\mathrm{X}$ & $6531 / \mathrm{K}-36.0$ & Fig. 27-28 \\
\hline 28. Pseudoschizaea rubina & $\mathrm{X}$ & $\mathrm{X}$ & $6422 / O-54.3$ & Fig. 29 \\
\hline 29. Phaeoceros laevis & $\mathrm{X}$ & $\mathrm{X}$ & $6469 / \mathrm{X}-46.3$ & Fig. 30 \\
\hline 30. Sphagnum & $\mathrm{X}$ & $\mathrm{X}$ & $6435 / G-46.4$ & Fig. 31 \\
\hline 31. Dicksonia sellowiana & $\mathrm{X}$ & $\mathrm{X}$ & $6443 / \mathrm{X}-63.0$ & Fig. 32 \\
\hline 32. Cyatheaceae 1 & $\mathrm{X}$ & $\mathrm{X}$ & $6475 / \mathrm{S}-47.0$ & Fig. 33 \\
\hline 33. Cyatheaceae 2 & $\mathrm{X}$ & $\mathrm{X}$ & $6463 / \mathrm{B}-46.3$ & Fig. 34 \\
\hline 34. Cyatheaceae 3 & $\mathrm{X}$ & & $6435 / \mathrm{N}-43.1$ & Fig. 35 \\
\hline 35. Cyatheaceae 4 & $\mathrm{X}$ & & $6473 / \mathrm{H}-45.3$ & Fig. 36 \\
\hline 36. tipo Anograma & $\mathrm{X}$ & & 6466/C-59.4 & Fig. 37 \\
\hline 37. tipo Blechnum & $\mathrm{X}$ & $\mathrm{X}$ & $6435 / \mathrm{U}-47.3$ & Fig. 38 \\
\hline 38. Polypodium & $\mathrm{X}$ & $\mathrm{X}$ & $5421 / \mathrm{W}-47.1$ & Fig. 39 \\
\hline 39. tipo Pecluma pectinatiformi & $\mathrm{X}$ & $\mathrm{X}$ & $6440 / O-48.2$ & Fig. 40-41 \\
\hline 40. tipo Microgramma vacciniifolia & $\mathrm{X}$ & $\mathrm{X}$ & $6440 / \mathrm{G}-41.2$ & Fig. $42-43$ \\
\hline 41. tipo Dryopteris & $\mathrm{X}$ & $\mathrm{X}$ & $6420 / \mathrm{F}-28.0$ & Fig. $44-45$ \\
\hline 42. tipo Onychium & $\mathrm{X}$ & & $6443 / O-55.4$ & Fig. 46-47 \\
\hline 43. tipo Huperzia & $\mathrm{X}$ & $\mathrm{x}$ & $6440 / \mathrm{G}-41.2$ & Fig. 48 \\
\hline 44. Lycopodium clavatum & $\mathrm{X}$ & & $6525 / \mathrm{H}-65.4$ & Fig. 49 \\
\hline 45. Selaginella & $\mathrm{X}$ & $\mathrm{X}$ & $6462 / \mathrm{G}-64.0$ & Fig. 50 \\
\hline 46. Araucaria angustifolia & $\mathrm{X}$ & $\mathrm{X}$ & $6421 / \mathrm{C}-40.4$ & Fig. 51 \\
\hline 47. Podocarpus & $\mathrm{X}$ & $\mathrm{X}$ & $6443 / \mathrm{X}-63.0$ & Fig. 52-53 \\
\hline 48. Cápsula de Briófito & $\mathrm{X}$ & $\mathrm{X}$ & $6435 / \mathrm{N}-48.2$ & Fig. 54 \\
\hline 49. Mandíbulas & $\mathrm{X}$ & $\mathrm{X}$ & $5421 / Y-43.4$ & Fig. $55-58$ \\
\hline 50. Garras & $\mathrm{X}$ & $\mathrm{X}$ & $5425 / \mathrm{S}-50.0$ & Fig. 59-60 \\
\hline 51. Pêlos & $\mathrm{X}$ & $\mathrm{X}$ & $5425 / \mathrm{S}-44.2$ & Fig. 61-62 \\
\hline 52. Ovos de Platielmites & $\mathrm{X}$ & $\mathrm{x}$ & $5428 / \mathrm{K}-45.3$ & Fig. 63 \\
\hline 53. Palinoforaminífero indeterminadol & $\mathrm{X}$ & $\mathrm{x}$ & $6491 / \mathrm{M}-49.1$ & Fig. 64-65 \\
\hline 54. Palinoforaminífero indeterminado 2 & $\mathrm{X}$ & & $6491 / \mathrm{M}-49$ & Fig. 66 \\
\hline
\end{tabular}


imagens foram processadas nos softwares Corel DRAW e Corel PHOTO-PAINT versões 12.0. Todas as lâminas de estudo estão depositadas na Palinoteca do citado laboratório, sediado em Porto Alegre, RS, sob codificação MP-P (Coleção Estratigráfica).

\section{Resultados}

Para os níveis amostrados dos testemunhos de São João do Sul e Santa Rosa do Sul, foram identificados um total de 114 diferentes táxons, que mostram evidências de mudanças paleovegetacionais ao longo do perfil, ocorridas ao longo do Holoceno na região.

Os resultados preliminarmente obtidos apontam para um número relevante de elementos palinológicos. Nesta contribuição são descritos 54 táxons: 21 fungos (incluindo aqueles indeterminados), cinco algas, um acritarco, um "incertae sedis", dois briófitos, 15 pteridófitos, duas gimnospermas. Outros palinomorfos támbém são registrados: cápsula de briófito; fragmentos de invertebrados (artrópodes, mandíbulas, pêlos, garras) e dois palinoforaminíferos ideterminados.

\section{Fungos}

Reino: Fungi

Filo Glomeromycota

Classe Glomeromycetes

Ordem Glomerales

Família Glomeraceae

1. Glomus Tus. \& C. Tus.

Fig. 1

Descrição: clamidósporos elipsoidais a esferoidais, médios a grandes, coloração podendo variar de amarelo-claro a amarelo-escuro, superfície psilada, filamento de hifas cenocíticas formando um micélio ramificado.

Dimensões: diâmetro das vesículas: $15 \mu \mathrm{m}$, eixo maior: $70 \mu \mathrm{m}$, eixo menor: $40 \mu \mathrm{m}$.

Observações: segundo Neves \& Bauermann (2003), o gênero é citado para o Quaternário como tipo Rhizophagus Dang. (gênero atual) ou Rhizophagites (gênero fóssil, encontrado comumente em sedimentos pleistocênicos).

Dados ecológicos: fungos micorrízicos associados às raízes das plantas terrestres (Koske et al. 2004).

Ocorrências: Santa Rosa do Sul e São João do Sul.

Filo Ascomicota

Classe Ascomicetes

Ordem Sordariales

Família Sordariaceae

2. Gelanispora calospora (Mouton) C. Moreau \& M. Moreau Fig. 2

Descrição: ascósporos elipsoidais, médios, asseptados, castanho-escuro, superfície psilada, poros circulares de pequena dimensão e densamente distribuídos.
Dimensões: eixo maior do ascósporo: $30 \mu \mathrm{m}$, eixo menor: $20 \mu \mathrm{m}$, dimensão dos poros: $2 \mu \mathrm{m}$.

Observação: espécie citada para o Quaternário como Gelasinospora adjuncta Cain.

Dados ecológicos: são decompositores de excrementos de animais, madeiras carbonizadas e lignina (van Geel 1978).

Ocorrências: Santa Rosa do Sul e São João do Sul.

3. Gelanispora reticulispora (Cain \& Greiss-Dengler) C. $\&$ M. Moreau

Fig. 3

Descrição: ascósporos elipsoidais, médios, asseptados, castanho-escuro, superfície psilada, com poros circulares densamente distribuídos.

Dimensões: eixo maior do ascósporo: $30 \mu \mathrm{m}$, eixo menor: $20 \mu \mathrm{m}$, dimensão dos poros: $4 \mu \mathrm{m}$.

Observação: espécie citada para o Quaternário com a sinonímia de Gelasinospora retispota Cain. (Neves \& Bauermann 2003). Diferencia-se de Gelanispora calaspora por apresentar menor número de poros e consequentemente poros com maior dimensão (Hooghiemstra 1984).

Dados ecológicos: idem ao anterior.

Ocorrências: Santa Rosa do Sul e São João do Sul.

\section{Neurospora}

Fig. 4

Descrição: esporos monosseptados, médios, com duas células afiladas nas extremidades, castanho- escuro e superfície com estrias longitudinalmente dispostas.

Dimensões: eixo maior: $25-30 \mu \mathrm{m}$, eixo menor: 10-20 $\mu \mathrm{m}$.

Observação: a identificação deste táxon baseou-se no trabalho de Hooghiemstra (1984), que descreve esta forma para o Quaternário da Colômbia como “tipo 361".

Dados ecológicos: não foi possível atribuir hábitat a esse esporo, sabe-se que está associado com outros fungos saprofíticos e é relacionado como sendo de sedimentação continental ocorrendo em ambientes úmidos (van Geel 1978).

Ocorrências: Santa Rosa do Sul e São João do Sul.

\section{Helicoon pluriseptatum Beverw}

Fig. 5

Descrição: conídio de disposição helicoidal, médios, mutiseptados, castanho-escuro e superfície psilada.

Dimensões: eixo maior: $35 \mu \mathrm{m}$.

Observação: a identificação deste táxon baseou-se no trabalho de van Geel (1978), que descreve esta forma como “tipo 30".

Dados ecológicos: o gênero Helicoon compreende espécies aero-aquáticas, que geralmente crescem sobre folhas submergidas, em condições de baixa oxigenação (van Geel 1978).

Ocorrências: Santa Rosa do Sul e São João do Sul. 
Filo Ascomycota

Classe Ascomycetes

Ordem Dothideales

Família Microthyriaceae

6. Microthyrium Desm.

Fig. 6

Descrição: ascósporos discóides, grandes, castanho-escuro, margens estriadas de tonalidade clara na porção externa, ostíolo de contorno irregular e tonalidade escura na zona central.

Dimensões: diâmetro da estrutura: 55-85 $\mu \mathrm{m}$, diâmetro do ostíolo: $2 \mu \mathrm{m}$.

Dados ecológicos: constituem representantes da família Microthyriaceae, ocorrendo como epífitos, com ampla distribuição nas regiões tropicais (van Geel 1978; Dilcher 1965).

Ocorrências: Santa Rosa do Sul e São João do Sul.

Ordem Helotiales

Família Helotiaceae

7. Bryophytomyces sphagni (Navashin) Cif.

Fig. 7

Descrição: esporos esferoidais, médios, hialinos, superfície psilada providas de muros que formam desenhos poligonais.

Dimensões: diâmetro do esporo: $25 \mu \mathrm{m}$, diâmetro das placas: $5 \mu \mathrm{m}$.

Observações: espécie comumente citada para o Quaternário como Tilletia sphagnii Navashin (Roth \& Lorscheitter 2008).

Dados ecológicos: conforme van Geel (1978) ocorre como parasitas de várias espécies do gênero Sphagnum (Dill.) Hedw.

Ocorrências: Santa Rosa do Sul e São João do Sul.

Ordem Magnaporthales

Família Magnaporthaceae

8. tipo Gaeumannomyces $\mathrm{cf}$. caricis J. Walker

Fig. 8

Descrição: esporângios, pequenos, castanho-escuro, superfície psilada, margens lobadas e poro central pouco visível.

Medidas: diâmetro do esporângio: 17-25 $\mu \mathrm{m}$.

Observações: espécie muito semelhante à descrita como tipo Entophlystis lobata Willoughby \& Townley (van Geel 1978).

Dados ecológicos: conforme Von Arx (1974), estes fungos ocorrem como parasitas ou saprófitas de caules e raízes de Poaceae.

Ocorrências: Santa Rosa do Sul e São João do Sul.

Filo Basydiomycota

Classe Basydiomycetes

Ordem Aphyllophorales

Família Corticiaceae

9. tipo Athelia Pers.

Fig. 9
Descrição: estruturas com aspecto circular-elipsoidais, médios, constituída por agrupamento de células pequenas, superfície psilada e de coloração castanho escuro.

Dimensões: diâmetro das estruturas: 30-50 $\mu \mathrm{m}$, diâmetro das células: 5-10 $\mu \mathrm{m}$.

Observações: esta forma foi descrita por Hooghiemstra (1984) como "tipo cf. Athelia".

Dados ecológicos: Kirk et al. (2001) relaciona espécies deste gênero como patógenos de líquens e algas.

Ocorrências: Santa Rosa do Sul e São João do Sul.

Classe Deuteromycetes

Ordem Moniliales

Família Dematiaceae

10. tipo Nigrospora Zimm.

Fig. 10

Descrição: conídiosporos elípticos, pequenos, castanho-escuro, superfície psilada e espessa com um poro característico.

Dimensões: eixo maior dos conídios: 15-20 $\mu \mathrm{m}$.

Dados ecológicos: representantes do gênero Nigrospora são relacionados a regiões quentes, onde ocorrem como fungos de solos de florestas, pastagens, manguezais, solos arenosos, além de serem decompositores de excrementos de Chiroptera (Domsch et al. 1980).

Ocorrências: Santa Rosa do Sul e São João do Sul.

\section{Esporos indeterminados}

\section{Esporo indeterminado 1}

Fig. 11

Descrição: ascósporos, grandes, castanho-claro, margens estriadas e tonalidade clara.

Dimensões: diâmetro maior da estrutura: $60 \mu \mathrm{m}$, diâmetro menor: $30 \mu \mathrm{m}$.

Observações: esta estrutura lembra morfologicamente o tipo Microthyrium, entretanto se diferencia pelas dimensões e sua forma.

Ocorrências: Santa Rosa do Sul e São João do Sul.

\section{Esporo indeterminado 2}

Fig. 12

Descrição: esporos fusiformes, médios, castanho-escuro, apresentando números variáveis de septos e com envoltório hialino formando dobras irregulares por toda a superfície.

Dimensões: eixo maior dos ascósporos: $30-40 \mu \mathrm{m}$, eixo menor: $10-15 \mu \mathrm{m}$.

Ocorrências: Santa Rosa do Sul e São João do Sul.

\section{Esporo indeterminado 3}

Fig. 13

Descrição: esporos monosseptados, tamanho variado (médios a grandes) com duas células afiladas nas extremidades, castanho-escuro e superfície psilada. 
Dimensões: eixo maior: 35-55 $\mu \mathrm{m}$, eixo menor: 12-20 $\mu \mathrm{m}$. Ocorrências: Santa Rosa do Sul e São João do Sul.

\section{Esporo indeterminado 4}

Fig. 14

Descrição: esporos polisseptados, tamanho variado (médios a grandes), castanho-escuro, superfície psilada, podendo ou não ser encontrado em forma plano-espiral.

Dimensões: eixo maior: $45-55 \mu \mathrm{m}$, eixo menor: 15-25 $\mu \mathrm{m}$.

Ocorrências: Santa Rosa do Sul e São João do Sul.

\section{Esporo indeterminado 5}

Fig. 15

Descrição: esporos fusiformes, médios, castanho-escuro, superfície com estrias irregulares longitudinalmente dispostas e com pequenas perfurações.

Dimensões: eixo maior dos ascósporos: $30 \mu \mathrm{m}$, eixo menor: $15 \mu \mathrm{m}$.

Ocorrências: Santa Rosa do Sul e São João do Sul.

\section{Esporo indeterminado 6}

Fig. 16

Descrição: ascósporo polisseptados (oito células), tamanho variado (médios a grandes), castanho-escuro, terminações claras, superfície psilada com pequenas perfurações mais visíveis na região mediana.

Dimensões: eixo maior dos ascósporos: $30-60 \mu \mathrm{m}$, eixo menor: $15-25 \mu \mathrm{m}$.

Ocorrências: Santa Rosa do Sul.

\section{Esporo indeterminado 7}

Fig. 17

Descrição: ascósporo polisseptados (cinco células), tamanho variado (médios a grandes), castanho- escuro, superfície psilada e com células diminuindo de tamanho em direção as extremidades (apresentando uma das extremidades com uma projeção).

Dimensões: eixo maior dos ascósporos: 30-50 $\mu \mathrm{m}$, eixo menor: $15-20 \mu \mathrm{m}$.

Ocorrências: Santa Rosa do Sul.

\section{Esporo indeterminado 8}

Fig. 18

Descrição: esporos esferoidais, médios, amarelo-escuro, com protuberâncias de tamanho uniforme e ápice truncado e ramificado.

Dimensões: diâmetro do esporo: 40-50 $\mu \mathrm{m}$, diâmetro das projeções: 4-6 $\mu \mathrm{m}$.

Ocorrências: Santa Rosa do Sul.

\section{Esporo indeterminado 9}

Fig. 19
Descrição: esporos esferoidais, médios, castanho-escuro, com inúmeras protuberâncias tuberculadas de tamanho uniforme e ápice arredondado.

Dimensões: diâmetro maior: entre 20-30 $\mu \mathrm{m}$.

Ocorrências: Santa Rosa do Sul.

\section{Esporo indeterminado 10}

Fig. 20

Descrição: corpos de frutificações, médios, castanho, com uma membrana composta por arranjos radiais não septados e ostíolo com cerca de oito projeções.

Dimensões: diâmetro maior: $40-50 \mu \mathrm{m}$.

Ocorrências: Santa Rosa do Sul.

\section{Hifas}

Fig. 21

Descrição: filamentos simples ou irregularmente ramificados, tamanho variado, castanho-escuro a castanho-claro.

Dimensões: variáveis.

Ocorrências: Santa Rosa do Sul e São João do Sul.

\author{
Algas \\ Reino: Protista \\ Divisão Chlorophyta \\ Classe Chlorophyceae \\ Ordem Clhorococcales \\ Família Dyctyosphaeriaceae
}

22. Botryococcus Kützing

Fig. 22

Descrição: colônias de células lobadas de aspecto irregular, tamanho variado, amarelo a castanho-escuro, superfície psilada formada por diversos indivíduos unicelulares.

Dimensões: colônias de dimensões variáveis entre 5 e $15 \mu \mathrm{m}$.

Dados ecológicos: o gênero ocorre em ambientes dulciaquícolas como águas de turfeiras parálicas, poças e lagoas de água doce (Medeanic 2006).

Ocorrências: Santa Rosa do Sul e São João do Sul.

Classe Zygnemaphyceae

Ordem Zygnemales

Família Zygnemataceae

23. Debarya (de Bary) Witt.

Fig. 23

Descrição: zigósporos, médios, formados por duas valvas radialmente simétricas. Cada hemisfério dividido em uma zona central plana e uma zona periférica levemente estriada radialmente.

Dimensões: diâmetro da região central: 25-30 $\mu \mathrm{m}$, diâmetro da zona periférica: $35-40 \mu \mathrm{m}$.

Dados ecológicos: estas algas foram caracterizadas como de ambientes dulciaquícolas de condições mesotróficas (van Geel \& van der Hammen 1977).

Ocorrências: Santa Rosa do Sul e São João do Sul. 

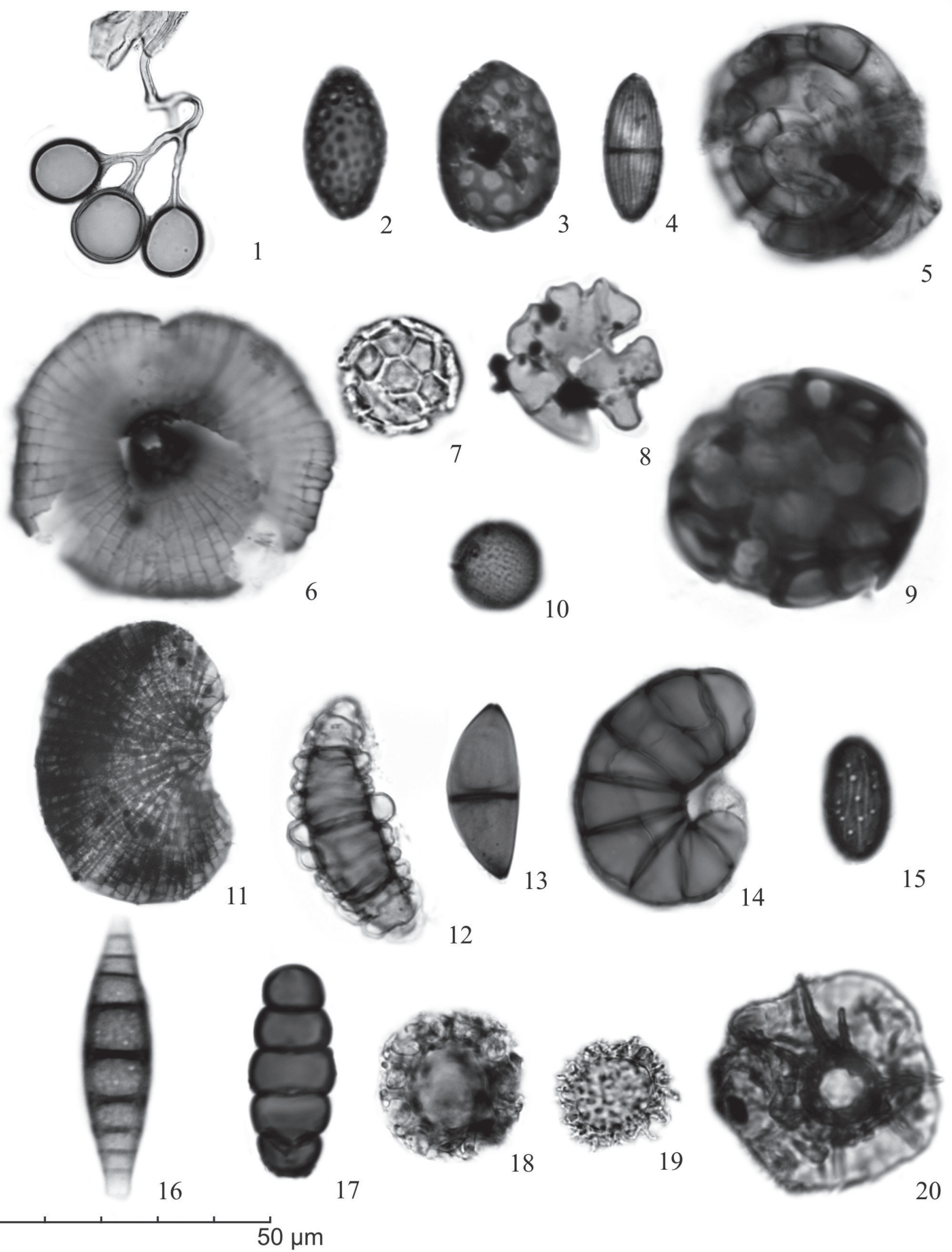

12
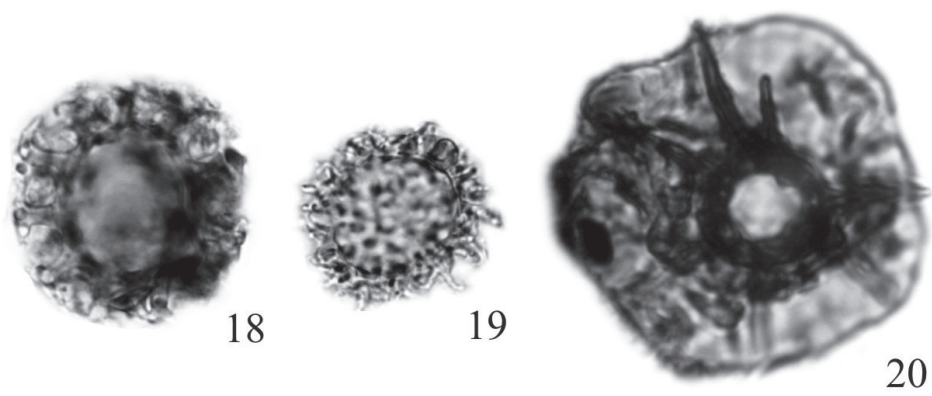

Figura 2. Fotomicrografias de palinomorfos selecionados. Esporos: 1. Glomus; 2. Gelanispora calospora; 3. Gelanispora reticulispora; 4. Neurospora cf.; 5. Helicoon pluriseptatum; 6. Microthyrium; 7. Bryophytomyces sphagni; 8. tipo Gaeumannomyces; 9. tipo Athelia; 10. tipo Nigrospora; 11. Esporo indeterminado 1; 12. Esporo indeterminado 2; 13. Esporo indeterminado 3; 14. Esporo indeterminado 4; 15. Esporo indeterminado 5; 16. Esporo indeterminado 6; 17. Esporo indeterminado 7; 18. Esporo indeterminado 8; 19. Esporo indeterminado 9; 20. Esporo 10. Escala gráfica $=50 \mu \mathrm{m}$. 


\section{4. tipo Mougeotia laetevires C. A. Agardh}

Fig. 24

Descrição: zigósporos, médios, hialinos, cilíndricos e cônicos, abrindo-se em duas valvas cilíndricas. Dimensões: eixo equatorial da valva maior: $25 \mu \mathrm{m}$; eixo menor: $15 \mu \mathrm{m}$.

Observação: a identificação baseou-se no trabalho de Hooghiemstra (1984), que descreve esta forma para o Quaternário como tipo 400.

Dados ecológicos: o gênero Mougeotia C. A. Agardh é característico de ambientes de água doce (Joly 2002).

Ocorrências: Santa Rosa do Sul e São João do Sul.

\section{Spirogyra Link}

Fig. 25

Descrição: zigósporos elípticos ou de forma alongada, médios a grandes, variando de hialinos a escurecidos, alguns apresentam membrana hialina.

Dimensões: diâmetro maior: $90 \mu \mathrm{m}$, diâmetro menor: $30 \mu \mathrm{m}$.

Dados ecológicos: segundo Bourrely (1966), trata-se de um gênero típico de água doce.

Ocorrências: Santa Rosa do Sul e São João do Sul.

\section{Zygnema C. A. Agardh}

Fig. 26

Descrição: zigósporos esferoidais a elipsoidais, médios, hialinos, superfície psilada com uma série de reentrâncias circulares regularmente distribuídas por toda a superfície.

Dimensões: eixo maior dos zigósporos: 35-50 $\mu \mathrm{m}$, diâmetro das cavidades: $5 \mu \mathrm{m}$.

Dados ecológicos: gênero atribuído a ambientes de água doce e solos úmidos com pouca profundidade (van Geel \& van der Hammen 1977; Joly 2002).

Ocorrências: Santa Rosa do Sul e São João do Sul.

\section{Grupo Acritarchas Evitt 1963}

\section{7. tipo Micrhystridium}

Fig. 27-28

Descrição: cistos globosos, pequenos, hialino com diminutas espinescências.

Dimensões: diâmetro: $18 \mu \mathrm{m}$, espinescências: $1 \mu \mathrm{m}$.

Dados ecológicos: Staplin (1961) registrou este gênero desde o Devoniano, fazendo parte do microplâncton marinho.

Ocorrências: Santa Rosa do Sul e São João do Sul.

\section{"Incertae sedis" \\ 28. Pseudoschizaea rubina Rossignol ex Christop.}

Fig. 29

Descrição: estruturas circulares em vista polar e elípticas em vista equatorial, médios, hialinas, inaperturadas, apresentando estrias finas e concêntricas dispostas paralelamente em vista equatorial. Dimensões: diâmetro das estruturas em vista polar: entre 30-50 $\mu \mathrm{m}$.
Dados ecológicos: Rossignol (1962) descreve esta espécie como sendo essencialmente de águas dulciaquícolas.

Ocorrências: Santa Rosa do Sul e São João do Sul.

\section{Briófitos}

Divisão Anthocerotophyta

Classe Anthocerotopsida

Ordem Anthocerotales

Família Anthocerotaceae

29. Phaeoceros laevis (L.) Prosk.

Fig. 30

Descrição: esporos triletes, grandes, bifurcados nas extremidades (padrão triqueto), heteropolares, radiossimétricos, circulares a subtriangulares e exospório microequinado. Espinhos muito finos e pequenos, quando presentes.

Dimensões: diâmetro equatorial dos esporos: 55-65 $\mu \mathrm{m}$.

Dados ecológicos: esta espécie ocorre sobre solos úmidos e abrigados, sendo comuns em margens de arroios, rios, vertentes e campos úmidos (Menéndez 1962). Segundo Lorscheitter (1989), ocorrem como pequenos tufos sobre solos úmidos.

Ocorrências: Santa Rosa do Sul e São João do Sul.

\section{Sphagnum (Dill.) Hedw}

Fig. 31

Descrição: esporos triletes bifurcados, médios a grandes, heteropolares, radiossimétricos, subtriangulares em vista polar, hialinos e com superfície psilada. Exospório com característico espessamento.

Dimensões: diâmetro equatorial dos esporos: 45-55 $\mu \mathrm{m}$.

Dados ecológicos: segundo Irgang \& Gastal Jr. (1996) as espécies de Sphagnum ocorrem em ambientes ácidos vivendo como plantas emergentes e flutuantes, sendo o principal vegetal formador de turfeiras.

Ocorrências: Santa Rosa do Sul e São João do Sul.

\section{Pteridófitos}

Divisão Pteridophyta

Classe Filicopsida

Ordem Polypodiales

Família Dicksoniaceae

\section{Dicksonia sellowiana Hook}

Fig. 32

Descrição: esporos triletes, grandes, heteropolares, radiossimétricos, subtriangulares a triangulares em vista polar, zonas interangulares quase retas onde o exospório sofre um espessamento nas regiões angulares.

Dimensões: diâmetro equatorial dos esporos: aproximadamente $75 \mu \mathrm{m}$.

Dados ecológicos: espécie de hábito arborescente, típica de interior de matas úmidas (Lorscheitter et al. 1999). Segundo Sehnem (1978), trata-se de plantas de porte arborescente podendo chegar a $5 \mathrm{~m}$ de altura. Crescem preferencialmente em lugares pantanosos nas serras da região, mas 
também em encostas serranas e excepcionalmente também em banhados das baixadas.

Ocorrências: Santa Rosa do Sul e São João do Sul.

Família Cyatheaceae

\section{Cyatheaceae 1}

\section{Fig. 33}

Descrição: esporos triletes, médios a grandes, heteropolares, radiossimétricos, subtriangulares, psilados. Exospório apresentando espessamento maior nas regiões não anguladas.

Dimensões: diâmetro equatorial dos esporos: $45-55 \mu \mathrm{m}$.

Dados ecológicos: são fetos arborescentes das zonas tropicais e subtropicais (Tryon \& Tryon 1982). Conforme Lorscheitter et al. (1999), ocorrem em florestas tropicais de montanhas, florestas úmidas de montanha ou florestas nebulares. Muitas espécies são características da Mata Atlântica.

Ocorrências: São João do Sul e Santa Rosa do Sul.

\section{Cyatheaceae 2}

Fig. 34

Descrição: esporos triletes, médios a grandes, heteropolares, radiossimétricos, subtriangular a triangular em vista polar, psilados. Exospório apresentando espessamentos menor nas regiões anguladas.

Dimensões: diâmetro equatorial dos esporos: 45-55 $\mu \mathrm{m}$.

Dados ecológicos: idem a Cyatheaceae 1 .

Ocorrências: Santa Rosa do Sul.

\section{Cyatheaceae 3}

Fig. 35

Descrição: esporos triletes, médios a grandes, heteropolares, radiossimétricos, subtriangular a triangular em vista polar, psilados com corpo central apresentando com castanho escuro. Exospório apresentando espessamentos uniformes.

Dimensões: diâmetro equatorial dos esporos: $45-65 \mu \mathrm{m}$.

Dados ecológicos: idem a Cyatheaceae 1 .

Ocorrências: Santa Rosa do Sul.

\section{Cyatheaceae 4}

Fig. 36

Descrição: esporos triletes, médios, heteropolares, radiossimétricos, triangular em vista polar. Zonas interangulares quase retas onde o exospório sofre um pequeno espessamento nas regiões angulares. Dimensões: diâmetro equatorial dos esporos: $35-45 \mu \mathrm{m}$.

Dados ecológicos: idem a Cyatheaceae 1.

Ocorrências: Santa Rosa do Sul.

Família Pteridaceae

36. tipo Anogramma

Fig. 37
Descrição: esporos triletes, médios a grandes, heteropolares, radiossimétricos, triangular em vista polar. Zonas interangulares arredondadas, exospório com espessamento evidente e uniforme.

Dimensões: diâmetro equatorial dos esporos: $65-75 \mu \mathrm{m}$.

Observações: a identificação deste táxon se baseou no trabalho de Spalding \& Lorscheitter (2009).

Dados ecológicos: este gênero ocorre como terrícola em áreas úmidas e em variados ambientes (Tryon

\& Tryon 1982).

Ocorrências: Santa Rosa do Sul.

Família Blechnaceae

\section{7. tipo Blechnum L.}

Fig. 38

Descrição: esporos monoletes, grandes, heteropolares, bilaterais, elípticos em vista polar e plano-convexo em vista equatorial, amarelo-claro a escuro e apresentando exospório psilado.

Dimensões: diâmetro polar dos esporos: $35-45 \mu \mathrm{m}$, diâmetro equatorial: 60-70 $\mu \mathrm{m}$.

Dados ecológicos: conforme Tryon \& Tryon (1982), representam plantas terrestres, rupestres, raramente epífitas, amplamente distribuídas na América tropical, ocorrendo em pântanos, interior de matas paludosas, bordas florestais e áreas antropizadas.

Ocorrências: Santa Rosa do Sul e São João do Sul.

Família Polypodiaceae

38. Polypodium L.

Fig. 39

Descrição: esporos monoletes, médios a grandes, heteropolares, bilaterais, e forma elíptica em vista polar e plano-convexa em vista equatorial. Exospório verrucado com distribuição regular das verrugas por toda superfície.

Dimensões: diâmetro polar dos esporos: $35-55 \mu \mathrm{m}$, diâmetro equatorial: 60 - $70 \mu \mathrm{m}$.

Observações: diferencia-se do tipo Micrograma vacciniifolia por apresentar verrugas uniformes por toda a superfície.

Dados ecológicos: epífitos sobre árvores ou rochas, mais raramente terrestres. Gênero muito numeroso em espécies, espalhado por toda a terra, mas sobretudo nos trópicos do antigo e novo mundo (Sehnem 1970).

Ocorrências: Santa Rosa do Sul e São João do Sul.

\section{9. tipo Pecluma pectinatiformis (Lindm.) M.G. Price} Fig. 40-41

Descrição: esporos monoletes, médios a grandes, heteropolares, bilaterais, e forma elíptica em vista polar e plano-convexa em vista equatorial. Exospório com verrugas robustas distribuídas de forma irregular por toda superfície.

Dimensões: diâmetro polar dos esporos: $45-55 \mu \mathrm{m}$, diâmetro equatorial: 60-70 $\mu \mathrm{m}$. 

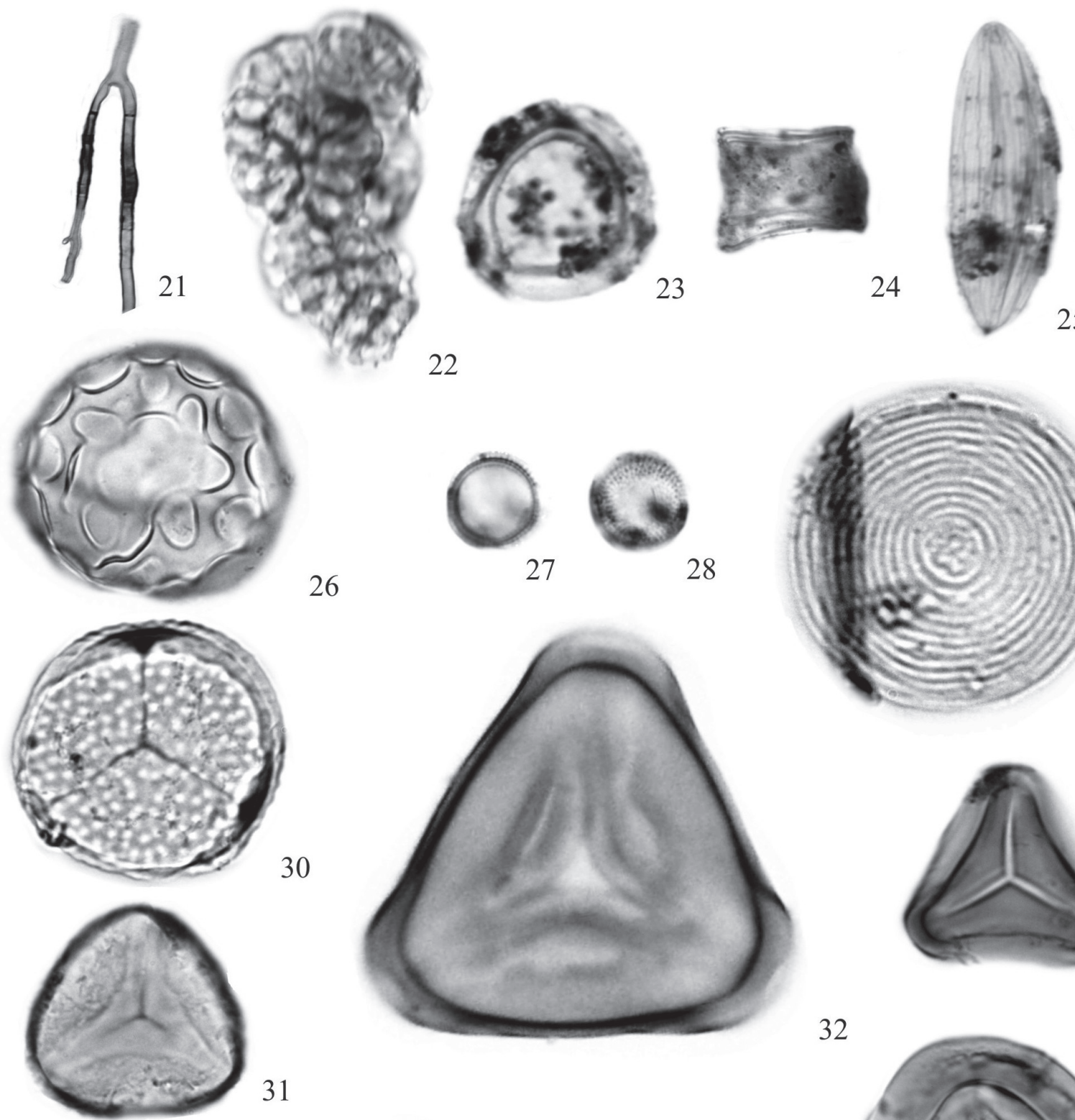

30
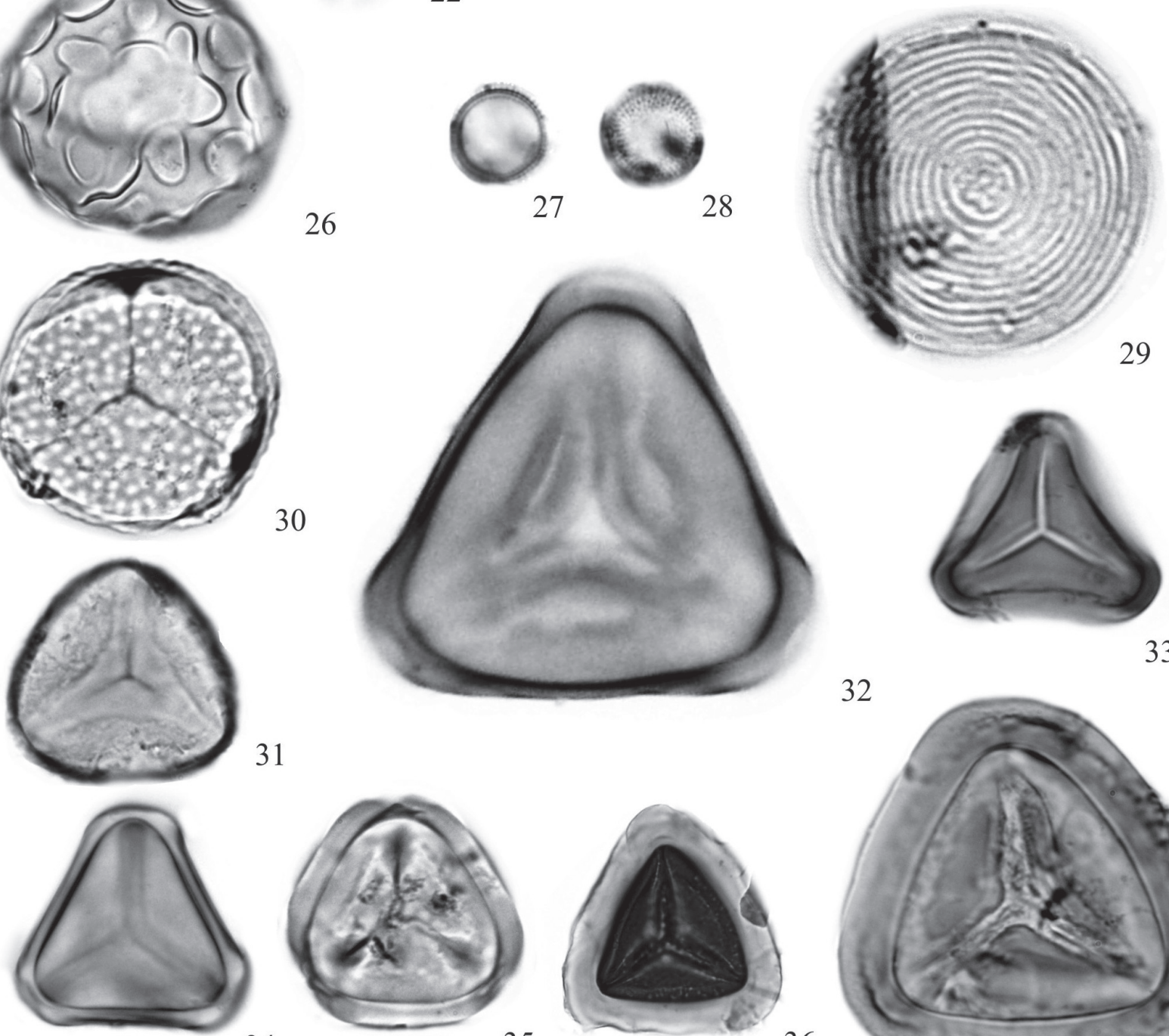

31

\section{4}
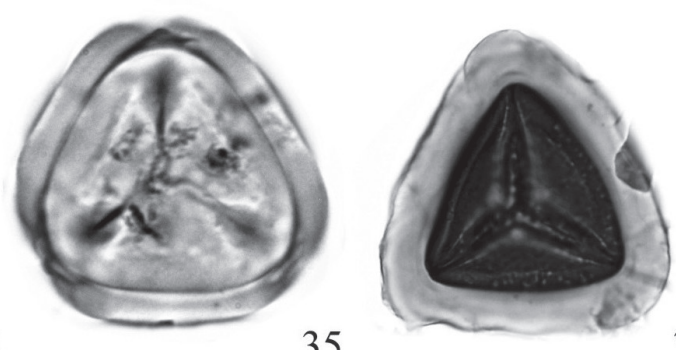

36
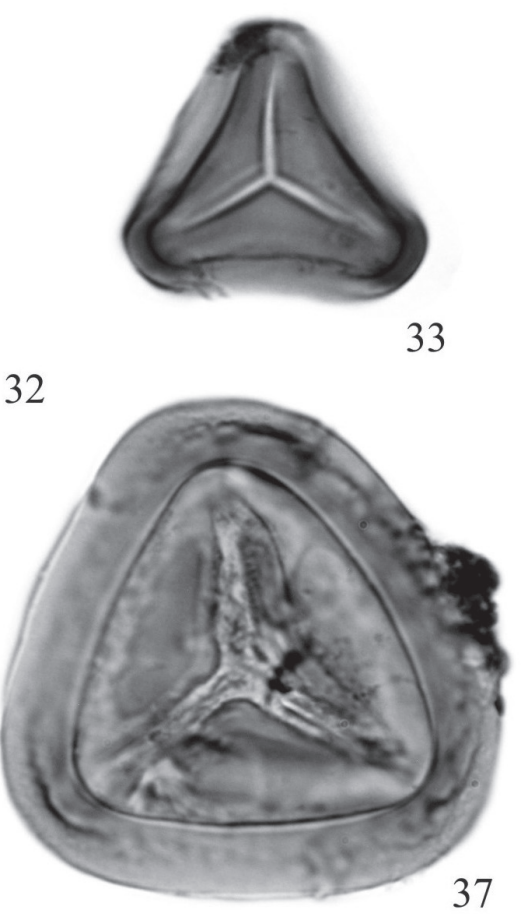

0

$50 \mu \mathrm{m}$

Figura 3. Fotomicrografias de palinomorfos selecionados. Hifas: 21. Hifas. Algas: 22. Botryococcus; 23. Debarya; 24. tipo Mougeotia laetevires; 25. Spirogyra; 26. Zygnema. Acritarcha: 27-28. tipo Micrhystridium; "Insertae sedis": 29. Pseudoschizaea rubina. Briófitos: 30. Phaeoceros laevis 31. Sphagnum. Pteridófitos: 32 . Dicksonia sellowiana; 33. Cyatheaceae 1; 34. Cyatheaceae 2; 35. Cyatheaceae 3; 36. Cyatheaceae 4; 37. tipo Anograma. Escala gráfica $=50 \mu \mathrm{m}$. 
Dados ecológicos: segundo Lorscheitter et al. (2005), trata-se de plantas epifíticas ocasionalmente epipétricas ou terrícolas, em florestas.

Ocorrências: Santa Rosa do Sul e São João do Sul.

40. tipo Microgramma vacciniifolia (Langst \& Fisch.) Copel.

Fig. 42-43

Descrição: esporos monoletes, grandes, heteropolares, bilaterais, e forma elíptica em vista polar e plano-convexa em vista equatorial. Exospório verrucado irregularmente por toda superfície.

Dimensões: diâmetro polar dos esporos: $35-45 \mu \mathrm{m}$, diâmetro equatorial: 60-70 $\mu \mathrm{m}$.

Dados ecológicos: segundo Lorscheitter et al. (2005) as espécies são relacionadas a ambientes sombreados e abertos.

Ocorrências: Santa Rosa do Sul e São João do Sul.

Família Aspidiaceae

41. tipo Dryopteris Adanson

Fig. 44-45

Descrição: esporos monoletes, médios a grandes, heteropolares, bilaterais, e forma elíptica em vista polar e plano-convexa em vista equatorial. Superfície apresentando exospório com projeções distribuídas de forma muito irregular.

Observação: Hooghiemstra (1984) descreve esta forma para o Quaternário da Colômbia como "tipo 343". A identificação baseou-se no trabalho de Lorscheitter (1984) e Neves (1991).

Dimensões: diâmetro polar dos esporos: 35 - $45 \mu \mathrm{m}$, diâmetro equatorial: 45 - $55 \mu \mathrm{m}$.

Dados ecológicos: segundo Sehnem (1974), ocorrem diversas espécies do gênero Dryopteris no interior da Mata Fluvial Atlântica. Também são passíveis de ocorrer nas demais matas, sempre em locais úmidos.

Ocorrências: Santa Rosa do Sul e São João do Sul.

Família Adiantaceae

42. tipo Onychium

Fig. 46-47

Descrição: esporos, grandes, heteropolares, radiais, superfície ornamentada por estrias grosseiras intercaladas por saliências (báculas).

Dimensões: eixo equatorial: $55 \mu \mathrm{m}$, eixo polar: $35 \mu \mathrm{m}$.

Observação: a identificação baseou-se no trabalho de Hooghiemstra (1984), que descreve esta forma para o Quaternário como "tipo 421".

Dados ecológicos: não foi possível identificar a determinação ecológica para este táxon.

Ocorrências: Santa Rosa do Sul.

Classe Lycopodiopsida

Ordem Lycopodiales
Família Lycopodiaceae

43. tipo Huperzia cf.

Fig. 48

Descrição: esporos triletes, médios, heteropolares, radiossimétricos, subtriangulares, superfície psilada e com pequenas perfurações.

Dimensões: diâmetro equatorial dos esporos: aproximadamente $40 \mu \mathrm{m}$.

Observações: esta forma foi descrita por Hooghiemstra (1984), como tipo Lycopodium faveolate, "tipo 299".

Dados ecológicos: segundo Scherer \& Lorscheitter (2008), este gênero ocorre como epífito ou rupestre, no interior ou nas bordas das matas e em locais úmidos.

Ocorrências: São João do Sul e Santa Rosa do Sul.

\section{Lycopodium clavatum $\mathrm{L}$.}

Fig. 49

Descrição: esporos triletes, médios, heteropolares, radiossimétricos, subtriangulares em vista polar com exospório reticulado.

Dimensões: diâmetro equatorial dos esporos: $35-45 \mu \mathrm{m}$.

Observações: diferencia-se dos esporos de L. clavatum adicionados nas amostras para cálculos de concentração polínica por apresentarem coloração mais clara.

Dados ecológicos: são plantas terrícolas atribuídas à ambientes semi-abertos (Tryon \& Tryon 1982).

Ocorrências: Santa Rosa do Sul.

Ordem Selaginellales

Família Selaginellaceae

45. Selaginella P. Beauv

Fig. 50

Descrição: esporos triletes, médios, heteropolares, radiossimétricos, subtriangulares a circulares em vista polar e apresentando exospório baculado.

Dimensões: diâmetro equatorial dos esporos: $30 \mu \mathrm{m}$, comprimento das báculas: $3 \mu \mathrm{m}$.

Dados ecológicos: de acordo com Lorscheitter et al. (1998), são plantas terrícolas encontradas em ambientes úmidos.

Ocorrências: Santa Rosa do Sul e São João do Sul.

\section{Gimnospermas}

Divisão Coniferophyta

Classe Coniferopsida

Ordem Coniferales

Família Araucariaceae

46. Araucaria angustifolia (Bertol.) Kuntze

Fig. 51

Descrição: grãos de pólen mônades, grandes, isopolares, aproximadamente esféricos, circulares, inaperturados e ornamentação levemente escabrada. Exina fina e delicada podendo ser observado como um grão irregularmente dobrado. 
Dimensões: diâmetro dos grãos: em torno de $65 \mu \mathrm{m}$.

Observações: esta espécie não ocorre na região de estudo. A presença de grãos de pólen de Araucaria angustifolia deve-se ao transporte anemófilo de espécies advindas do Planalto, onde a espécie ocorre como elemento da Floresta Ombrófila Mista (Mata com Araucária). A determinação taxonômica baseou-se nos trabalhos de Roth \& Lorscheitter (2008) e Macedo et al. (2009).

Ocorrências: Santa Rosa do Sul e São João do Sul.

Família Podocarpaceae

47. Podocarpus L' Hér. ex Pers.

Fig. 52-53

Descrição: grãos de pólen mônades, grandes, vesiculados (bissacados), heteropolares, bilaterais. Corpo central aproximadamente elipsoidal com leptoma no pólo distal e apresentam sacos aéreos com retículo de malhas irregulares.

Dimensões: comprimento total (incluindo sacos): 50$65 \mu \mathrm{m}$, diâmetro polar do corpo central: cerca de $20 \mu \mathrm{m}$, diâmetro equatorial do corpo central: $35 \mu \mathrm{m}$, altura dos sacos aéreos: $25 \mu \mathrm{m}$.

Dados ecológicos: no estado de Santa Catarina ocorrem duas espécies deste gênero, Podocarpus lambertii Klotzsch ex Endl., com distribuição na Floresta Ombrófila Mista (Mata com Araucária), (Backes \& Irgang 2004) e P. sellowii Klotzsch ex Endl., com distribuição na Floresta Ombrófila Densa (Reitz et al. 1988). P. lambertii é considerada uma espécie pioneira, precursora em campos e orlas de bosques com excelente regeneração natural em vegetação secundária (Carvalho 2003), em todas as áreas de ocorrência prefere encostas de morros, ravinas e outros sítios úmidos (Marchiori 2005). P. sellowii é associada a uma espécie secundária tardia não tolerando baixas temperaturas (Carvalho 2006). Segundo Barth (1962) não é possível distinguir palinologicamente as duas espécies.

Ocorrências: Santa Rosa do Sul e São João do Sul.

\section{Outros palinomorfos}

48. Cápsula de Briófito

Fig. 54

Descrição: estruturas reticuladas com abertura apical (geralmente encontrados na posição de feto).

Dimensões: podem variar de 100-300 $\mu \mathrm{m}$.

Ocorrências: Santa Rosa do Sul e São João do Sul.

\section{Fragmentos de invertebrados \\ 49. Mandíbulas}

Fig. 55-58

Descrição: são representadas por estruturas dentiformes que podem variar de robustas a frágeis. Dimensões: podem entre 20-50 $\mu \mathrm{m}$.

Observações: estruturas mandibulares morfologicamente comparáveis a mandíbulas de anelídeos poliquetas onde são comumente chamados de Escolecodontes, entretanto não se descarta a possibilidade de alguns deles serem rádulas de gastrópodes, conforme sugerido pelas ilustrações do trabalho de Calvo (1987).

Ocorrências: Santa Rosa do Sul e São João do Sul.

50. Pêlos

Fig. 59-60

Descrição: são formas filamentosas, alongadas, apresentando aspecto de estruturas pilosas que podem variar de tamanho e espessura.

Dimensões: podem variar entre 10-50 $\mu \mathrm{m}$.

Ocorrências: Santa Rosa do Sul e São João do Sul.

\section{Garras}

Fig. 61-62

Descrição: são representadas por formas alongadas e pontiagudas e podem variar de tamanho e espessura.

Dimensões: podem entre 5-25 $\mu \mathrm{m}$.

Ocorrências: Santa Rosa do Sul e São João do Sul.

\section{Ovos de Platielmites}

Fig. 63

Descrição: são estruturas alongadas, hialinas, com abertura em uma das extremidades e muitas vezes com pedúnculo na extremidade oposta.

Dimensões: cerca de $100 \mu \mathrm{m}$.

Dados ecológicos: segundo Ruppert \& Barnes (1996), são formas dulciaquícolas que vivem em fundos de lagos, lagoas, córregos e nascentes, sendo algumas espécies ocorrendo na serrapilheira de porções muito úmidas.

Ocorrências: Santa Rosa do Sul e São João do Sul.

Reino Protista

Filo Foraminifera

\section{Palinoforaminífero indeterminado 1}

Fig. 64-65

Descrição: testas internas quitinosa de microforaminíferos de formato trocoespirais, com câmaras hialinas com reentrâncias. Corpo composto por câmaras lisas em número variável.

Dimensões: podem variar entre $50-150 \mu \mathrm{m}$.

Dados ecológicos: inúmeros trabalhos palinologia apontam estes elementos como sendo de ambiente marinho (Pedrão \& Carvalho 2002).

Ocorrências: Santa Rosa do Sul e São João do Sul.

\section{Palinoforaminífero indeterminado 2}

Fig. 66

Descrição: testas internas quitinosa de microforaminíferos em forma planoespirais, com câmaras hialinas com reentrâncias. Corpo composto por câmaras ornamentadas em número variável.

Dimensões: podem variar de 100-150 $\mu \mathrm{m}$.

Dados ecológicos: idem a Palinoforaminífero 1.

Ocorrências: Santa Rosa do Sul. 


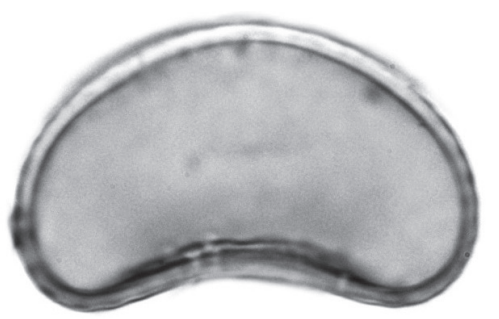

38

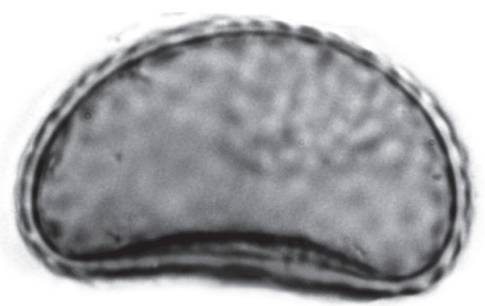

39
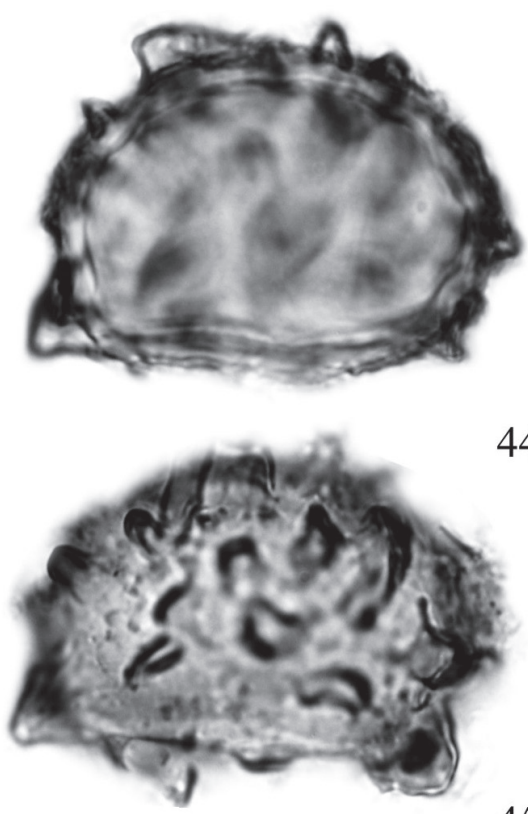

45

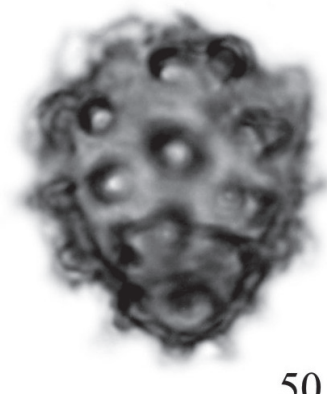

50

$$
0
$$
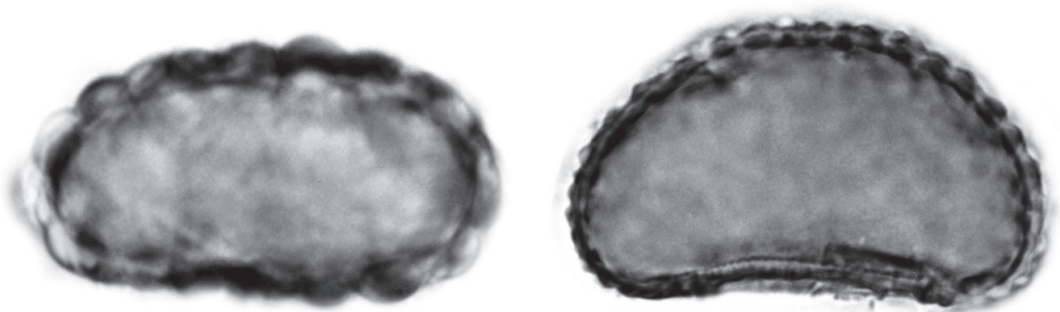

40

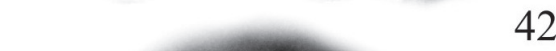

42

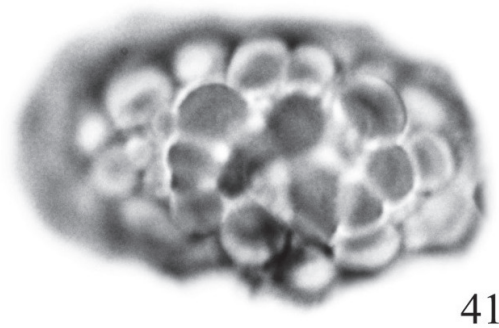

41

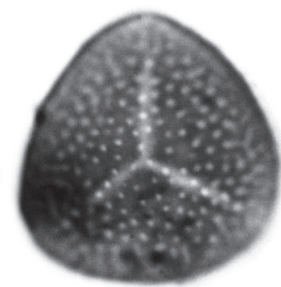

48

46

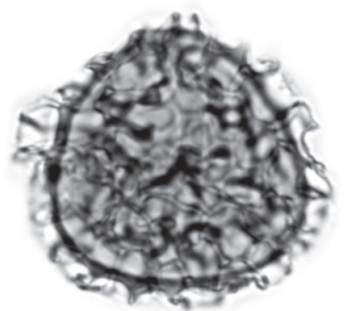

49
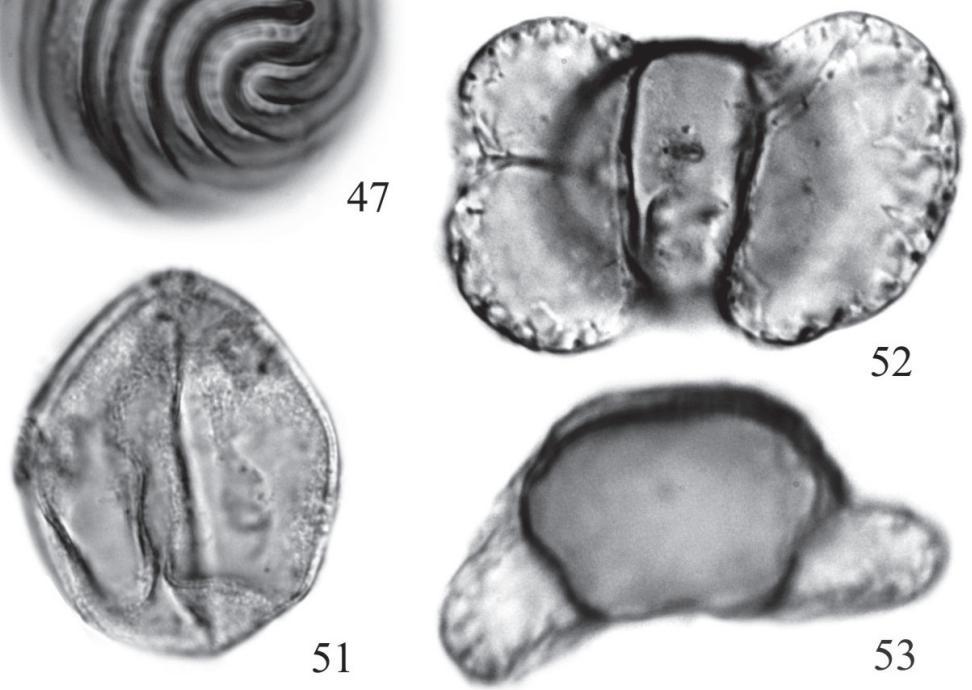

47

Figura 4. Fotomicrografias de palinomorfos selecionados. 38. tipo Blechnum; 39. Polypodium; 40-41. tipo Pecluma pectinatiformi; 42-43. tipo Microgramma vacciniifolia; 44-45. tipo Dryopteris; 46-47. tipo Onychium; 48. tipo Huperzia; 49. Lycopodium clavatum; 50. Selaginella. Gimnospermas: 51. Araucaria angustifolia; 52-53. Podocarpus. Escala gráfica $=50 \mu \mathrm{m}$. 


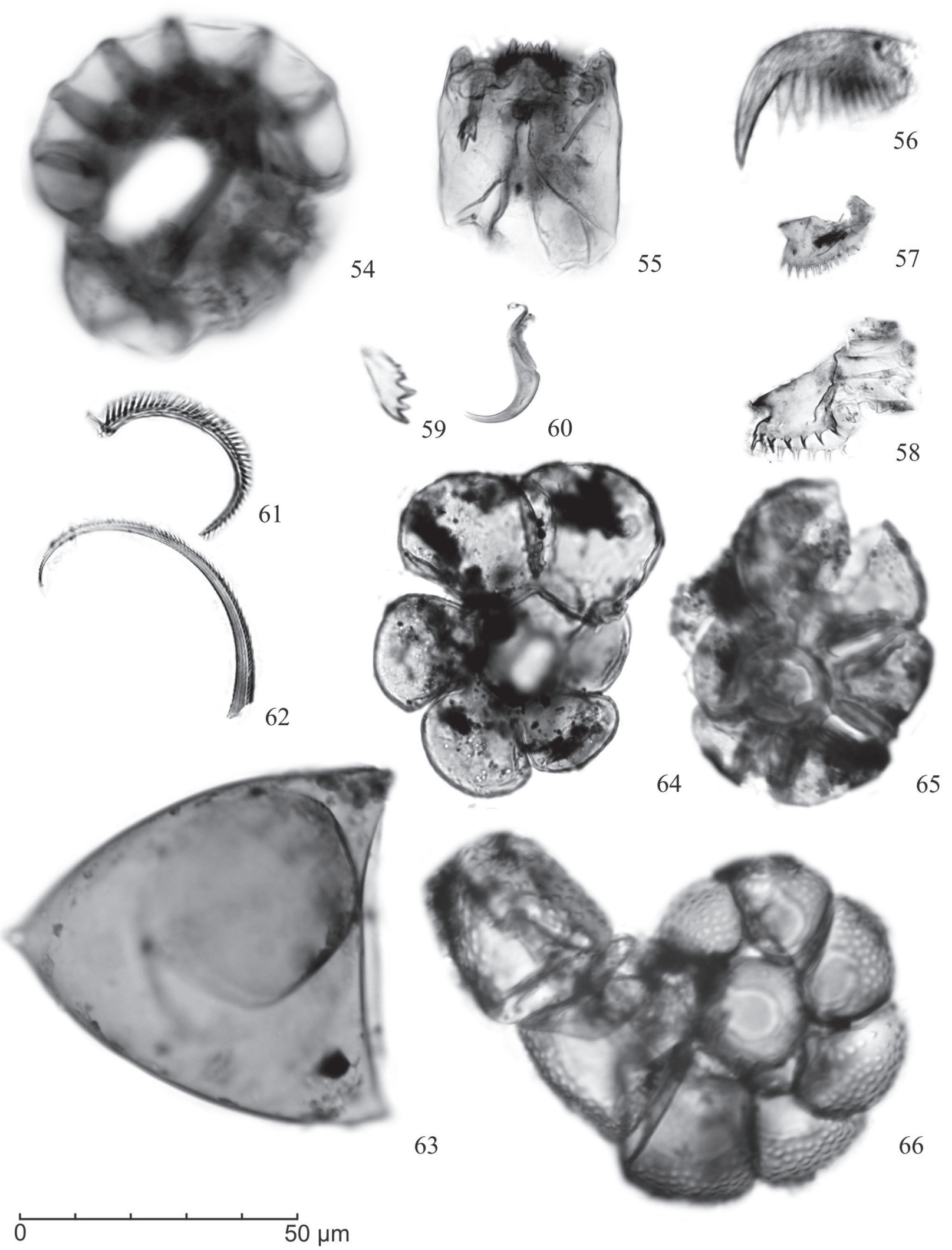

Figura 5. Fotomicrografias de palinomorfos selecionados: Outros palinomorfos: 54. Cápsula de Briófito; 55-58. Mandíbulas; 59-60. Garras; 61-62. Pêlos; 63. Ovos de Platielmites; Palinoforaminíferos: 64-65. Palinoforaminífero indeterminado 1; 66. Palinoforaminífero indeterminado 2. Escala gráfica $=50 \mu \mathrm{m}$. 


\section{Considerações finais}

Este trabalho documenta os palinomorfos registrados em duas perfurações holocênicas (7908 \pm 30 anos AP-atual), na Planície Costeira Sul de Santa Catarina, com a descrição e ilustração de 54 táxons, constituindo o primeiro trabalho dessa natureza para o Holoceno da região. Dentre os dois poços analisados, verifica-se uma maior diversidade para o perfil de Santa Rosa do Sul, que soma 54 táxons, em detrimento àqueles oriundos dos sedimentos de São João do Sul (43 táxons). Os táxons ausentes neste último perfil são relativos a esporos de fungos (esporos indeterminados 6-10), representantes das Cyatheaceae (Cyatheaceae 3-5), tipo Onychium, Lycopodium clavatum e palinoforaminífero indeterminado 2. As descrições dos grãos de pólen angiospérmicos, bem como as informações quantitativas e as respectivas interpretações paleoecológicas constituem parte das próximas contribuições em finalização pelos autores.

\section{Agradecimentos}

Este trabalho é parte de um estudo maior que vem sendo realizado na Planície Costeira do Rio Grande do Sul e de Santa Catarina, sob os auspícios da FAPERGS (processo 1012119). O primeiro autor agradece ao CNPq pela concessão da bolsa de Doutorado (processo 140924/2008-6).

\section{Referências Bibliográficas}

Alexopoulos, C.J.; Mims, C.W. \& Blackwell, M. 1996. Introductory Mycology. 4 ed. New York, John Wiley \& Sons.

Backes, P. \& Irgang, B. 2004. Mata Atlântica: as árvores e a paisagem. Porto Alegre, Paisagens do Sul.

Barth, O.M. 1962. Catálogo sistemático dos pólens das plantas arbóreas do Brasil Meridional - Parte Complementar: Coniferales. Memorial do Instituto Oswaldo Cruz 60: 199-208.

Barth, O.M. \& Melhem, T.S. 1988. Glossário ilustrado de palinologia. Campinas, Unicamp.

Bauermann, S.G.; Neves, P.C.P.; Marques Toigo, M. \& Ashraf, A.R. 2005. Evidences of Holocene transgression on Domingos Petroli Swamp, southern coastal plain, Rio Grande do Sul, Brazil. Journal of Geoscientific Research in Nortbeast Asia 8(1): 98-103.

Behling, H. 1993. Untersuchungen zur spätpleistozänen und holozänen vegetations und klimageschichte der tropischen küstenwälder in Santa Catarina (südbrasilien).. Dissertationes Botanicae - Band 206, Berlin, Cramer.

Behling, H. 1995. Ahigth resolution Holocene pollen record from Lago do Pires, SE Brasil: vegetation and fire history. Jornal of Paleontology 14: 253-268.

Behling, H. 1998. Late vegetation and climatic changes in Brazil. Review of Paleobotany and Palynology 99:143-156.

Behling, H. 2002. South and southeast Brazilian grasslands during Late Quaternary times: a synthesis. Palaeogeography, Palaeoclimatology, Palaeoecology 117: 9-27.

Behling, H.; Bauermann, S.G. \& Neves, P.C.P. 2001. Holocene environmental changes from the São Francisco de Paula region, southern Brazil. Journal South American Earth Science 14: 631-639.

Behling, H.; \& Negrelle, R.R.B. 2001. Tropical rain forest and climate dynamics of the Atlantic lowland, southern Brazil, during the Late Quaternary. Quaternary Research 56: 383-389.

Behling, H.; Pillar, V. \& Bauermann, S.G. 2004. Late Quaternary Araucaria forest, grassland (Campos), fire and climate dynamics, inferred from a high-resolution pollen record of Cambará do Sul in southern Brazil. Palaeogeography, Palaeoclimatology, Palaeoecology 203: 277-297.

Behling, H.; Pillar, V.; Müller, S.C. \& Overbeck, G. 2007. Late-Holocene fire history in a forest-grassland mosaic in southern Brazil: Implications for conservation. Applied Vegetation Science 10: 81-90.

Bold, H.C.; Alexopoulos, C.J. \& Delevoryas, T. 1987. Morphology of Plants and Fungi. 5. ed. New York, Harper \& Row.

Bourrely, P. 1966. Les algues d'eau douce. Initiatiion á la systematique. I- Les algues vertes. Paris, N. Boulce \& Cie de Paris.

Burjack \& Marques-Toigo, 1980. Burjack, M.I., Marques-Toigo, M., 1980. Caracterização palinológica da Turfeira da região de águas Claras, Município de Viamão- RS, Brasil. Boletim do Instituto de Geociencias 11: 31-189.

Calvo, I.S. 1987. Rádulas de gastrópodes marinhos brasileiros. Rio Grande, Editora da Fundação Universidade do Rio Grande.

Carvalho, P.E.R. 2003. Espécies arbóreas brasileiras. v. 1. Brasília, Embrapa.

Carvalho, P.E.R. 2006. Espécies arbóreas brasileiras. v. 2. Brasília, Embrapa.

Colinvaux, P.A.; de Oliveira, P.E.; Patiño, J.E.M. 1999. Amazon Pollen Manual and Atlas. Singapore, Harwood Academic Publishers.

De Oliveira, P.E.; Behling, H.; Ledru, M.P.; Barberi, M.; Bush, M.; SalgadoLabouriau, M.L.; Garcia, M.J.; Medeanic, S.; Barth, O.M.; Barros, M.A. \& Schell-Ybert, R. 2005. Paleovegetação e paleoclimas do Quaternário do Brasil. In: Souza, C.R.G.; Suguio, K.; Oliveira, A.M.S. \& De-Oliveira, P.E. (Eds.). Quaternário do Brasil. Ribeirão Preto, Holos.

Diehl, F.L. \& Horn filho, N.O. 1996. Compartimentação geológicageomorfológica da zona litorânea e planície costeira do estado de Santa Catarina. Notas Técnicas 9: 90-93.

Dilcher, D.L. 1965. Epiphyllous fungi from Eocene deposits in western Tennessee, U.S.A. Palaeontographica 116: 1-54.

Domsch, K.H.; Gams, W. \& Anderson, T.H. 1980. Compendium of soil fungi. London, academic press.

Erdtman, G. 1952. Pollen morphology and plant taxonomy - angiosperms. Stockholm, Almqvisit \& Wiksell.

Faegri, K. \& Iversen, L. 1989. Textbook of pollen analysis. $4^{\text {th }}$ ed. New York, Jonh Wiley \& Sons.

Guiry, M.D. \& Dhonncha, E. 2004. Algae database. World electronic publication. http://www.algaebase.com (Acesso em 16/01/2010).

Heusser, C.J. 1971. Pollen and Spores of Chile. Arizona, The University Arizona Press.

Hooghiemstra, H. 1984. Vegetational and climatic history of the high plain of bogotá, colombia: a continuous record of the last 3,5 million years. Amsterdam, Strauss \& Cramer.

IBGE. 1992. Manual técnico da vegetação brasileira. Rio de janeiro, Fundação Instituto Brasileiro de Geografia e Estatística.

International Index Fungorum, 2009. http://www.speciesfungorum.org (Acesso em 16/01/2010).

Irgang, B.E. \& Gastal Jr. C.V. de S. 1996. Macrófitas aquáticas da Planície Costeira do RS. Porto Alegre, Produção independente.

Joly, A.B. 2002. Botânica: introdução à taxonomia vegetal. 13 ed. São Paulo, Editora Nacional.

Kirk, P.M.; Cannon, P.F.; David, J.C. \& Stalpers, J.A. 2001. Dictionary of the fungi. 9 ed. Cambridge, $C A B$ International.

Klein, R.M. 1978. Flora ilustrada catarinense: mapa fitogeográfico do Estado de Santa Catarina. Itajaí, Herbário Barbosa Rodrigues, V parte - mapa fitogeográfico.

Koske, R.E; Gemma, J.N.; Corkidi, L.; Sigüenza, C. \& Rincón, E. 2004. Arbuscular Mycorhyzas in Coastal Dunes. In: Martinez, M.L. \& Psuty, N.P. (Eds.) Coastal Dunes Ecology and Conservation, SpringerVerlag 173-88.

Leal, M.G. \& Lorscheitter, M. L. 2006. Pólens, esporos e demais palinomorfos de sedimentos holocênicos de uma floresta paludosa, Encosta Inferior do Nordeste, Rio Grande do Sul, Brasil. Iheringia, Série Botânica 61(2): 13-47.

Leal, M.G. \& Lorscheitter, M.L. 2007. Plant sucession in a forest on the Lower Northeast Slopes of Serra Geral, Rio Grande do Sul, and Holocene palaeoenvironments, Southern Brazil. Acta Botanica Brasilica 21(1): 1-10. 
Leonhardt, A. \& Lorscheitter, M.L. 2007. Palinomorfos do perfil sedimentar de uma turfeira em São Francisco de Paula, Planalto Leste do Rio Grande do Sul, Sul do Brasil. Revista Brasileira de Botânica 30: 47-59.

Lorscheitter, M.L. \& Romero, E.J. 1985. Palynology of Quaternary sediments of the core T15, Rio Grande Cone, South Atlantic, Brazil. Quaternary of South America and Antarctic Peninsula 3: 55-91.

Lorscheitter, M.L. 1983. Evidences of sea oscillations of the Late Quaternary in Rio Grande do Sul, Brazil, provide by palynological studies. Quaternary of South America and Antarctic Peninsula 1: 53-60.

Lorscheitter, M.L. 1984. Palinologia de sedimentos quaternários do Cone de Rio Grande. Tese de Doutorado em Geociências, Instituto de Geociências, Universidade Federal do Rio Grande do Sul, Porto Alegre.

Lorscheitter, M.L. 1988. Palinologia de sedimentos quaternários do testemunho T15, Cone do Rio Grande, Atlântico Sul, Brasil. Pesquisas 21: 61-117.

Lorscheitter, M.L. 1989. Palinologia de sedimentos quaternários do testemunho T15, Cone do Rio Grande, Atlântico Sul, Brasil. Descrições taxonômicas - parte II. Pesquisas 22: 89-127.

Lorscheitter, M.L. 2003. Contribution to the Holocene history of Atlantic rain forest in the Rio Grande do Sul state, southern Brazil. Revista del Museo Argentino de Ciencias Naturales 5(2): 261-271.

Lorscheitter, M.L.; Ashraf, A.R.; Bueno, R.M. \& Mosbrugger, v. 1998. Pteridophyte spores of Rio Grande do Sul flora, Brazil. Part I. Palaeontographica 246: 1-113.

Lorscheitter, M.L.; Ashraf, A.R.; Windisch, P.G. \& Mosbrugger, v. 1999. Pteridophyte spores of Rio Grande do Sul flora, Brazil. Part II. Palaeontographica 251: 71-235.

Lorscheitter, M.L.; Ashraf, A.R.; Windisch, P.G. \& Mosbrugger, V. 2001. Pteridophyte spores of Rio Grande do Sul flora, Brazil. Part III. Palaeontographica 263:1-159.

Lorscheitter, M.L.; Ashraf, A.R.; Windisch, P.G. \& Mosbrugger, V. 2002. Pteridophyte spores of Rio Grande do Sul flora, Brazil. Part IV. Palaeontographica 270: 1-180.

Lorscheitter, M.L.; Ashraf, A.R.; Windisch, P.G. \& Mosbrugger, V. 2005. Pteridophyte spores of Rio Grande do Sul flora, Brazil. Part V. Palaeontographica 270: 1-180.

Lowe, J.J. \& Walker, M.J.C. 1987. Reconstructing quaternary environments. New York, John Wilwy.

Macedo, R.B.; Cancelli, R.R; Bauermann, S.G.; Bordignon, S. A. de L. \& Neves, P.C.P. das 2007. Palinologia de níveis do Holoceno da Planície Costeira do Rio Grande do Sul (localidade de Passinhos), Brasil. Gaea 7: 68-74.

Macedo, R.B.; Souza, P.A. \& Bauermann, S.G. 2009. Catálogo de pólens, esporos e demais palinomorfos em sedimentos holocênicos de Santo Antonio da Patrulha, Rio Grande do Sul, Brasil. Iheringia, Série Botânica 62(2): 43-78.

Macedo, R.B.; Souza, P.A.; Bauermann, S.G. \& Bordignon, S.A.L. 2010. Palynological analysis of a late Holocene core from Santo Antônio da Patrulha, Rio Grande do Sul, Southern Brazil. Anais da Academia Brasileira de Ciências 82: 731-745.

Mamede, M.C.H.; Cordeiro, I.; Rose, L.; Fiuza De Mello, M.M.da R. \& Oliveira, R.D.J. 2004. Mata Atlântica. In: MARQUES, O.A.V.\& DULEBA, W. (Eds.) 2004. Estação Ecológica Jureia-Itatins-ambiente físico, flora e fauna 115-151.

Marchiori, J.N.C. 2005. Dendrologia das Gimnospermas. 2a ed. Santa Maria: Ed. Universidade/UFSM.

Markgraf, V. \& D’ Antoni, H.L. 1978. Pollen Flora of Argentina. Arizona, The University Arizona Press.

Medeanic, S. 2006. Freshwater algal palynomorph records from Holocene depositsin the Coastal Plain of the Rio Grande do Sul, Brazil. Review of Palaeobotany and Palynology 141: 83-101.

Menéndez, G.G.H. 1962. Estudio de las Anthocerotales y Marchantiales de la Argentina. Tucumán, Universidad Nacional de Tucumán, Instituto Miguel Lillo.

Moore, P.D.; Webb, J.A. \& Collinson, M.E. 1991. Pollen analysis. Blackwell Scientific Publications.

Neves, P.C.P. \& Bauermann, S.G. 2003. Catálogo palinológico de coberturas quaternárias do Estado do Rio Grande do Sul (Guaíba e Capão do Leão), Brasil. Descrições Taxonômicas Parte - I: fungos, algas, palinomorfos outros e fragmentos de invertebrados. Pesquisas, Série Botânica 53: 121-149.

Neves, P.C.P. \& Bauermann, S.G. 2004. Catálogo palinológico de coberturas quaternárias do Estado do Rio Grande do Sul (Guaíba e Capão do Leão), Brasil. Descrições Taxonômicas Parte - II: Bryophyta e Pteridophyta. Pesquisas, Série Botânica 55: 227-251.

Neves, P.C.P. \& Cancelli, R.R. 2006. Catálogo palinológico em sedimentos do final do Neógeno no Estado do Rio Grande do Sul (Guaíba e Capão do Leão), Brasil. Taxonomia Parte - IV: Magnoliophyta I (Magnoliopsida). Gaea 2(2): 75-89.

Neves, P.C.P. \& Lorscheitter, M.L. 1992. Palinologia de sedimentos de uma Mara tropical paludosa em Terra de Areia, Rio Grande do Sul, Brasil. Descrições taxonômicas, Parte I: Fungos, algas, briófitos, pteridófitos, palinomorfos outros e fragmentos de invertebrados. Acta Geológica Leopoldensia 15(36): 83-114.

Neves, P.C.P. \& Lorscheitter, M.L. 1995a. Palinologia de Sedimentos de uma Mata Tropical Paludosa (Terra de Areia, Planície Costeira Norte, Rio Grande do Sul, Brasil). Descrições taxonômicas - Parte II: Gimnospermas e Angiospermas. Acta Geológica Leopoldensia 18(41): 45-82.

Neves, P.C.P. \& Lorscheitter, M.L. 1995b. Upper Quaternary palaeoenvironments in the Northern Coastal Plain of Rio Grande do Sul, Brazil. Quaternary of South America and Antarctic Peninsula 9: 39-67.

Neves, P.C.P. \& Lorscheitter, M. L. 1996. Feições de uma Mata Tropical Paludosa em Terra de Areia, Planície Costeira Norte, Rio Grande do Sul, Brasil. Notas técnicas II 9(1): 28-38.

Neves, P.C.P. 1991. Palinologia de sedimentos de uma Mara tropical paludosa em Terra de Areia, Rio Grande do Sul. Dissertação de Mestrado Geociências, Instituto de Geociências, Universidade Federal do Rio Grande do Sul, Porto Alegre.

Neves, P.C.P. 1998. Palinologia de sedimentos quaternários no estado do Rio Grande do Sul, Brasil: Guíba e Capão do Leão. Tese de doutorado. Programa de Pós-graduação em Geociências, Universidade Federal do Rio Grande do Sul.

Nimer, E. 1979. Climatologia do Brasil. Rio de Janeiro, Instituto Brasileiro de Geografia e Estatistica/Departamento de Recursos Naturais e Estudos Ambientais.

Pedrão, E. \& Carvalho, M.A. 2002. Os fósseis da Bacia de Sergipe/Alagoas. Os palinomorfos: palinoforaminíferos. Phoenix 34: 1-5.

Punt, W.; Blackmore, S.; Nilsson, S. \& Thomas, A. 2007. Glossary of pollen and spore terminology. Review of Palaeobotanic and Palynology 143: $1-81$.

Quadros, L.P. \& Melo, J.H.G. 1987. Método prático de preparação palinológica em sedimentos do Pré-Mesozóico. Boletim de Geociências da PETROBRAS 1: 205-214.

Reitz, R.; Klein, R.M. \& Reis, A. 1988. Projeto Madeira do Rio Grande do Sul. Porto Alegre, Corag.

Rossignol, M. 1962. Analyse pollinique de sediments marins quaternaires en Israel. II. Sédiments pleistocenes. Pollen et Spores 4: 122-148.

Roth, L. \& Lorscheitter, M.L. 2008. Palinomorfos de um perfil sedimentar em uma turfeira do Parque Nacional dos Aparados da Serra, leste do Planalto do Rio Grande do Sul, Brasil. Iheringia, Série Botânica 63(1): 69-100.

Roubik, D.W. \& Moreno, J.E. 1991. Pollen and Spores of Barro Colorado. St. Louis, Missouri Botanical Garden.

Ruppert, E.E. \& Barnes, R.D. 1996. Zoologia dos invertebrados. ("invertebrate Zoology"). 6 ed. São Paulo, Roca.

Staplin, F.L. 1961. Reef-controlled distribution of Devonian microplanktion in Alberta. Palaeontology 4(3): 392-424.

Scherer, C. \& Lorscheitter, M.L. 2008. Palinomorfos de fungos e criptógamas em sedimentos quaternários de duas matas com Araucária, Planalto leste do Rio Grande do Sul, Brasil. Acta Botanica Brasilica 22: 131-144.

Sehnem, A. 1970. Flora Ilustrada Catarinense. Polipodiácaeas, Itajaí, Herbário Barbosa Rodrigues.

Sehnem, A. 1974. Flora Ilustrada Catarinense. Esquiseáceas, Itajaí, Herbário Barbosa Rodrigues.

Sehnem, A. 1978. Flora Ilustrada Catarinense. Ciateáceas, Itajaí, Herbário Barbosa Rodrigues. 
Spalding, B.B.C. \& Lorscheitter, M.L. 2009. Palinologia de sedimentos da turfeira do Banhado Amarelo, São Francisco de Paula, Rio Grande do Sul, Brasil. Fungos e criptógamas. Hoehnea 36: 219-232.

Tryon, R.M. \& Tryon, A.F. 1982. Ferns and Allied Plants. New York, Springer-Verlag.

van Geel, B. \& van der Hammen, T. 1977. Zygnemataceae in Quaternary Colombian sediments. Review of Palaeobotany and Palynology 25(5): 377-392. van Geel, 1978. A palaeoecological study of Holocene peat bog sections in Germany and the Netherland, based on the analysis of pollen, spores and macro and microscopic remains of fungi, algae, cormophytes and animals. Review of Palaeobotany and Palynology 25: 1-120.

Villwock, J.A. \& Tomazelli, L.J. 1995. Geologia Costeira do Rio Grande do Sul. Notas Técnicas 8: 1-45.

Von Arx, J.A. 1974. The genera of fungi sporulating in pure cultura. Vaduz, A. R. Gantner-Verlag K.G. 